\title{
The Endoplasmic Reticulum Stress Response in Neuroprogressive Diseases: Emerging Pathophysiological Role and Translational Implications
}

\author{
Gerwyn Morris ${ }^{1,2} \cdot$ Basant K. Puri ${ }^{3} \cdot K$ Wen Walder ${ }^{4} \cdot$ Michael Berk $^{2,5,6,7,8} \cdot$ Brendon Stubbs $^{9,10,11} \cdot$ Michael Maes $^{2,12}$. \\ André F. Carvalho ${ }^{13,14}$
}

Received: 29 January 2018 / Accepted: 20 March 2018 / Published online: 29 March 2018

(C) The Author(s) 2018

\begin{abstract}
The endoplasmic reticulum (ER) is the main cellular organelle involved in protein synthesis, assembly and secretion. Accumulating evidence shows that across several neurodegenerative and neuroprogressive diseases, ER stress ensues, which is accompanied by over-activation of the unfolded protein response (UPR). Although the UPR could initially serve adaptive purposes in conditions associated with higher cellular demands and after exposure to a range of pathophysiological insults, over time the UPR may become detrimental, thus contributing to neuroprogression. Herein, we propose that immune-inflammatory, neuro-oxidative, neuro-nitrosative, as well as mitochondrial pathways may reciprocally interact with aberrations in UPR pathways. Furthermore, ER stress may contribute to a deregulation in calcium homoeostasis. The common denominator of these pathways is a decrease in neuronal resilience, synaptic dysfunction and even cell death. This review also discusses how mechanisms related to ER stress could be explored as a source for novel therapeutic targets for neurodegenerative and neuroprogressive diseases. The design of randomised controlled trials testing compounds that target aberrant UPR-related pathways within the emerging framework of precision psychiatry is warranted.
\end{abstract}

Keywords Neurodegeneration $\cdot$ Neuroprogression $\cdot$ Unfolded protein response $\cdot$ Mood disorders $\cdot$ Endoplasmic reticulum stress $\cdot$ Molecular neurobiology

Basant K. Puri

basant.puri@imperial.ac.uk

Tir Na Nog, Bryn Road seaside 87, Llanelli, Wales SA15 2LW, UK

2 IMPACT Strategic Research Centre, School of Medicine, Deakin University, Geelong, Australia

3 Department of Medicine, Imperial College London, Hammersmith Hospital, London, England W12 0HS, UK

4 The Centre for Molecular and Medical Research, School of Medicine, Deakin University, P.O. Box 291, Geelong 3220, Australia

5 Department of Psychiatry, University of Melbourne, Melbourne, Australia

6 Orygen, the National Centre of Excellence in Youth Mental Health, Parkville, Australia

7 Centre for Youth Mental Health, University of Melbourne, Melbourne, Australia
8 Florey Institute for Neuroscience and Mental Health, Melbourne, Australia

9 Physiotherapy Department, South London and Maudsley NHS Foundation Trust, London, UK

10 Health Service and Population Research Department, Institute of Psychiatry, Psychology and Neuroscience, King's College London, London, UK

11 Faculty of Health, Social Care and Education, Anglia Ruskin University, Chelmsford, UK

12 Department of Psychiatry, Chulalongkorn University, Bangkok, Thailand

13 Department of Psychiatry, Faculty of Medicine, University of Toronto, Toronto, ON, Canada

14 Centre for Addiction \& Mental Health (CAMH), Toronto, ON, Canada 


\section{Introduction}

The endoplasmic reticulum (ER) is a cell organelle that plays an indispensable role in protein synthesis, folding and sorting, as well as the delivery of proteins to their ultimate cellular destination. This role is facilitated by the presence of a multitude of chaperone proteins capable of binding to hydrophobic areas of newly synthesised, but as yet unfolded, proteins to facilitate optimal protein folding and prevent protein-protein aggregation. Under physiological conditions, protein folding and function are also facilitated by $\mathrm{N}$-linked glycosylation and the formation of disulphide bonds by reaction mechanisms favoured by the highly oxidative environment of the ER [1,2].

However, in pathophysiological circumstances, the accumulation of misfolded or unfolded proteins may ensue [2,3]. Several mechanisms may contribute to the accumulation of unfolded proteins, including an excessive biosynthesis of reactive oxygen species (ROS), a lowered efficiency of cellular anti-oxidant defences $[2,4]$, as well as disturbances in calcium homoeostasis [2, 3]. In addition, in diseases like amyloidosis and Huntington's disease the accumulation of misfolded proteins appears to be a pivotal pathophysiological event. In such circumstances, the ER initially elicits an adaptive or protective response described as the unfolded protein response (UPR) aimed at restoring homoeostasis within the organelle and the cell through the re-establishment of protein homeostasis [5-7]. Nevertheless, in some pathophysiological situations, the homeostatic capacity of the ER and the UPR may not meet cellular demands and may even become detrimental (vide infra), a condition referred to as ER stress. While severe and prolonged ER stress may trigger apoptotic cell death $[8,9]$, there is an accumulating body of evidence supporting the proposition that sub-lethal ER stress and the consequent chronic upregulation of the UPR are involved in the pathogenesis and pathophysiology of several diseases [10-12]. Figure 1 summarises the effects of upregulation of the UPR.

Exemplars of such illnesses include Alzheimer's disease $[13,14]$, Parkinson's disease [15, 16], multiple sclerosis [17, 18] and amyotrophic lateral sclerosis [19, 20]. More recently, a putative role of ER stress for psychiatric disorders in which neuroprogression may occur, including bipolar disorder [12, $21,22]$, major depressive disorder [23, 24] and schizophrenia, [25] has been disputed. It is noteworthy that the chronic upregulation of the UPR may lead to the development of chronic inflammation [26, 27], oxidative stress [11, 28, 29] and multiple dimensions of mitochondrial dysfunction [30-33] and that these elements appear to be shared factors involved in the pathogenesis and pathophysiology of neurodegenerative and neuroprogressive disease, although disease-specific elements also seem to be involved [34-39]. There is also some evidence to suggest that the detrimental effects of ER stress and chronic UPR upregulation could be "druggable" and hence inhibition of pathways involved in the UPR may confer

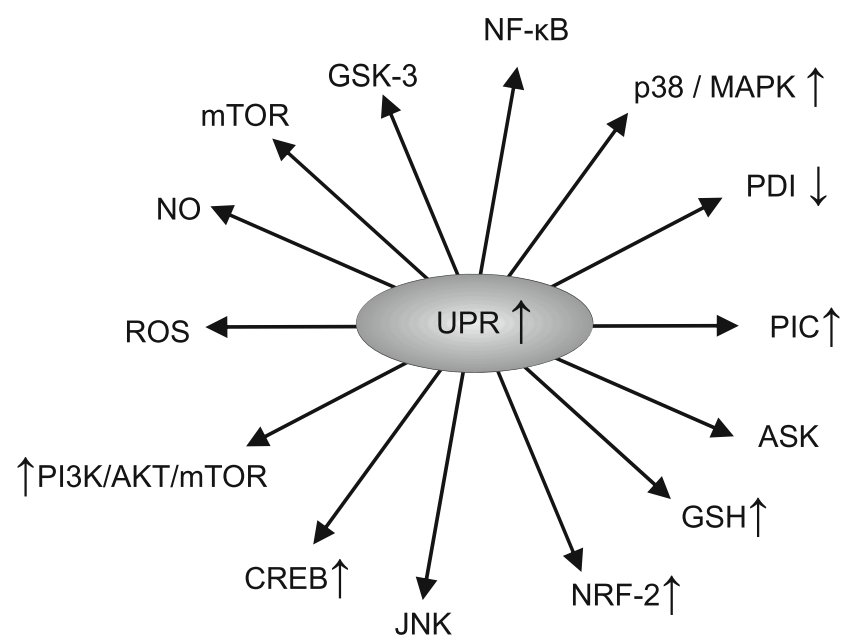

Fig. 1 Effects of the upregulation of the UPR

neuroprotection. For example, there are reports demonstrating that inhibition of ER stress pathways could protect against neuronal injury [40-42].

Thus, this review has two overarching aims: first, to detail putative pathways whereby activation of the UPR may instigate or exacerbate chronic inflammation, oxidative/nitrosative stress and multiple dimensions of mitochondrial dysfunction that are observed across neuroprogressive illnesses and, second, to examine therapeutic options targeting ER stress and the UPR as novel neurotherapeutic targets for neuroprogressive diseases. Initially, processes stemming from ER stress and UPR activation which may lead to the initiation or exacerbation of chronic neuroinflammation will be critically examined before moving on to a consideration of putative pathways leading to the initiation or exacerbation of oxidative and nitrosative stress, and multiple dimensions of mitochondrial dysfunction.

\section{ER Stress, Activation of the UPR and the Development of Chronic Inflammation}

\section{Processes Involved in the Activation of the UPR}

During the UPR, a triad of ER transmembrane protein receptors referred to as protein kinase RNA-like endoplasmic reticulum kinase (PERK), inositol-requiring enzyme $1 \alpha$ (IRE1 $\alpha)$ and activating transcription factor 6 (ATF6), whose activity is negatively regulated by the master ER chaperone GRP78, act as sensors to detect misfolded/mutant proteins [43, 44]. However, in an environment of ER stress, GRP78 binds to the exposed hydrophobic domains of unfolded or misfolded proteins leading to their dissociation from PERK, ATF6 and IRE1 $\alpha$, thus activating these ER signalling pathways [43]. Once activated, each of these receptors may undergo oligomerisation and other 
conformational changes, thus inducing highly specific downstream signalling cascades $[44,45]$.

\section{Activation of PERK and the Development of Chronic Inflammation}

PERK phosphorylates eukaryotic translation initiation factor$2 \alpha$ (eIF $2 \alpha$ ) leading to an inhibition of general protein translation and promotion of the preferential translation of transcription factor ATF4 [7, 46]. ATF4 in turn translocates to the nucleus whereupon it induces the transcription of additional UPR target genes and, in an environment of extreme ER stress, ATF4 targets the promoter of the gene that encodes the transcription factor $\mathrm{CHOP}$, which plays a major role in the instigation of apoptotic cell death [47] (see [48] for a review).

Activation of PERK leads to upregulation of the JAK1/STAT3 signalling axis and subsequent increments in the transcription and translation of IL-6 and oncostatin, thus forming a feed-forward loop driving escalating levels of inflammation [49]. It is noteworthy that activation of PERK in astrocytes, and subsequent paracrine activation of microglia, is now recognised as a relevant mechanism in the initiation and perpetuation of neuroinflammation [49]. PERK activation leads to phosphorylation of eIF $2 \alpha$, which also suppresses the translation of IKB, resulting in translocation of the cytosolic transcription factor NF-KB to the nucleus, whereupon it may induce the expression of genes involved in instigating and regulating inflammatory pathways [50]. Furthermore, PERK may also regulate cellular redox homoeostasis via the activation of nuclear factor erythroid 2-related factor 2 (Nrf2) and the subsequent upregulation of reduced glutathione [51-53]. It is also noteworthy that PERK-activated ATF4 also regulates the cellular redox state and may also act independently of PERK to induce the production of pro-inflammatory cytokines [50].

\section{Activation of ATF6 and the Development of Chronic Inflammation}

Upregulation of monomeric ATF6 also exerts a range of complex, broadly pro-inflammatory effects via the upregulation of NF- $K B$ via mechanisms involving activation of the CREB and $\mathrm{PI} 3 \mathrm{~K} / \mathrm{Akt} / \mathrm{mTOR}$ signalling pathways [50, 54]. The upregulation of this UPR pathway also exerts direct effects on inflammation via the upregulation of toll-like receptor activity on macrophages [55].

\section{Activation of IRE1a and the Development of Chronic Inflammation}

IRE1 $\alpha$ functions both as a kinase and as an endonuclease, which is activated via a process of oligomerisation in the absence of GRP78 inhibition. Evidence suggests that this enzyme could play a major role in regulating the splicing of several mRNAs and its activity is an indispensable player in the translation and activation of transcription factor X-box binding protein-1 (XBP-1) [56, 57]. XBP-1, in turn, increases the transcription of several UPR target genes including the one encoding GRP78 $[58,59]$. The activated IRE1 $\alpha$ can also form a multiprotein complex with apoptosis signal-regulating kinase 1 (ASK1), resulting in the upregulation of various intracellular signalling systems such as c-Jun N-terminal kinase (JNK) [60], p38/MAPK [61, 62], NF-KB [63, 64], glycogen synthase kinase 3 (GSK-3) [65, 66], mammalian target of rapamycin (mTOR) $[67,68]$ and the phosphatidylinositol 3kinase/protein kinase $\mathrm{B} / \mathrm{mTOR}$ (PI3K/AKT/mTOR) pathway [69-71]. These pathways also play a major role in determining the balance between cell survival and cell death, generally promoting cell survival in an environment of chronic oxidative stress. Yet it is important to note that their effects on cell survival are pleiotropic, and activation of these pathways may also drive cellular death in other circumstances, particularly when ER stress is severe [72, 73]. The net effect of these signalling systems is somewhat unpredictable as they engage in a complex pattern of mutual cross-talk with the UPR and each other, and their relative activities appear to influence the balance between cell proliferation and cell death [74-76]. Figure 2 illustrates the actions of the UPR.

For example, the UPR activates GSK-3, possibly via a route involving increased autophagy of the inactive kinase phosphorylated at serine 219 [65]. This kinase in turn also appears to play a role in the regulation of the UPR by influencing the phosphorylation status of CHOP and caspase-3 [66, 77]. There is also evidence of a bidirectional feedback between UPR activity and levels of mTOR signalling [78-80]. Similarly, the activation of NF-KB by the UPR also acts to reduce ER stress by accelerating the clearance of misfolded proteins via the modulation of autophagic activity [72]. Readers interested in a detailed consideration of the mechanisms enabling and regulating such "cross-talk", and how such communication leads to variations in biochemical and immunological profiles over time, are referred to previous scholarly reviews [81, 82]. Importantly, from the perspective of the aims of this paper, changes in the activity of $\mathrm{p} 38$ / MAPK, JNK, NF-kB, mTOR, GSK-3 and PI3K/AKT have pivotal roles in instigating and/or modulating inflammatory and immune pathways and the activity of peripheral mononuclear blood cells such as macrophages [83-87].

Several research teams have adduced data demonstrating that $\mathrm{p} 38 / \mathrm{MAPK}$ is a major player in the promotion and regulation of inflammatory and immune responses in general and that the upregulation of $\mathrm{p} 38 / \mathrm{MAPK}$ is a pivotal driver of proinflammatory cytokine transcription and translation [88]. Phosphorylation of NF-KB and a range of other transcription factors, such as myocyte enhancer factor-2 (MEF-2), as a 


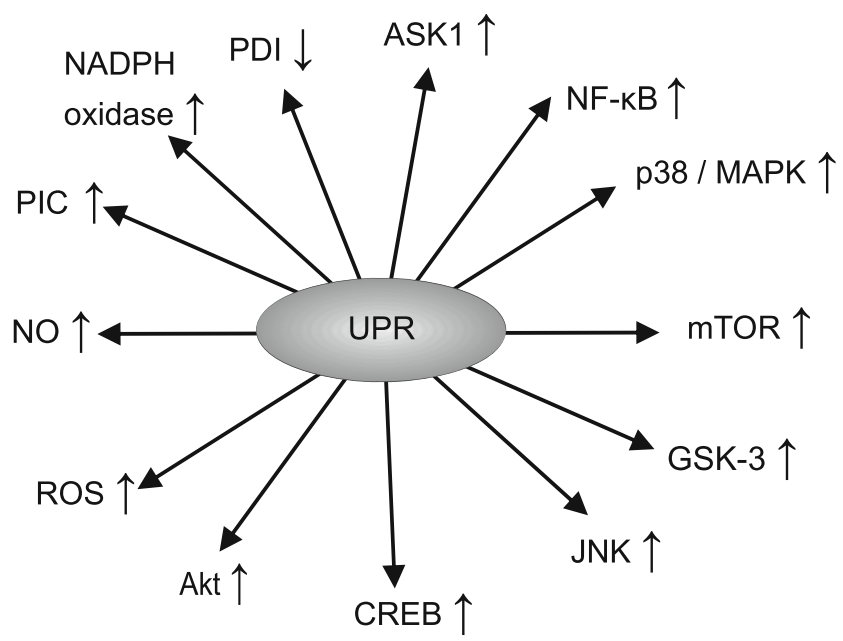

Fig. 2 Actions of the UPR

result of upregulated p38/MAPK activity induces transcriptional activation of tumour necrosis factor- $\alpha$ (TNF- $\alpha$ ), IL-6 and other pro-inflammatory cytokines [83, 89]. Similarly, there is copious evidence that activation of JNK signalling plays a major role in cytokine production and the subsequent development of inflammation [84, 90].

The NF-KB pathway also regulates the production of pro-inflammatory cytokines and several other processes driving the inflammatory response, such as leukocyte recruitment and the survival of peripheral mononuclear blood cells, which are important contributors to the inflammatory response [91, 92]. Furthermore, the complex bidirectional signalling between pro-inflammatory cytokines (notably TNF- $\alpha$ ) allows for the development of a self-amplifying inflammatory response [93, 94]. However, it should be noted that the anti-apoptotic activity of NF- $\mathrm{KB}$ may protect cells against the ravages of inflammation and in certain circumstances the pro-apoptotic properties of this signalling system can also contribute to the resolution of inflammation by contributing to the immunologically silent destruction of infiltrating leucocytes and macrophages [91].

The activity of GSK-3 influences the balance between the production of pro- and anti-inflammatory cytokines, $\mathrm{T}$ cell differentiation, toll-like receptor responses and the proliferation and activity of transcription factors which are known to play a regulatory role in the duration and magnitude of the immune response, such as signal transducer and activator of transcription (STAT), nuclear factor of activated $\mathrm{T}$ cells (NFAT), T-box transcription factor (Tbet) and NF- $\mathrm{KB}$ [95-97]. A recent review further illustrates the immunoregulatory role of GSK [98]. Much of this regulatory activity occurs in concert with mTOR and PI3K/AKT pathways [99]. These interactions are complex but are essentially connected with the role of mTOR as a metabolic sensor and its capacity to integrate metabolic and immune processes, thereby regulating the activation and proliferation of $\mathrm{T}$ cells, B cells and antigen presenting cells. Readers interested in a detailed consideration of the processes involved are invited to consult the work of Powell et al. [100] and Weichhart et al. [85]. It should also be noted that the PI3K/AKT/mTOR signalling axis has a broadly restraining effect on the development of chronic inflammation by limiting the production of type 1 interferons, while increasing the production of IL-10, and hence, its downregulation during chronic UPR activation may contribute to the development and perpetuation of an inflammatory state [86].

Given the above data, accumulating evidence supporting an association between the chronic upregulation of the UPR and the development of chronic inflammation is perhaps unsurprising $[26,65,70,101]$. It is also noteworthy that the chronic upregulation of pro-inflammatory cytokines in tandem with upregulation of NF- $\mathrm{kB}$ and $\mathrm{p} 38$ /MAPK may enhance the biosynthesis of ROS and nitric oxide (NO), and thus may promote or otherwise aggravate oxidative and nitrosative stress [87, 102-104], and hence provides a mechanism for the development of chronic oxidative stress accompanying acute or chronic upregulation of the UPR $[11,28,105]$. Moreover, the complex interplay of NF- $\mathrm{kB}$, p38/MAPK and ROS may lead to a self-amplifying pattern of redox dyshomoeostasis [106-108]. However, there are a number of other mechanisms which may also contribute to the development of oxidative and nitrosative stress following ER stress and over-activation of the UPR which seem underdiscussed, and we will now turn to a consideration of these factors.

\section{UPR Activation and the Development of Oxidative and Nitrosative Stress}

\section{Mechanisms Involved in the Development of Chronic Oxidative and Nitrosative Stress}

ER stress and the subsequent activation of the UPR may lead to an increased production of ROS and subsequently to oxidative stress via a number of mechanisms other than the upregulation of MAPK and NF-KB [105]. Such mechanisms involve an upregulation of protein disulphide isomerase (PDI) resulting in the activation of NADPH oxidase isomers, notably NOX-2 and NOX-4 [109], and the upregulation of oxidative protein folding in the ER, which rivals mitochondrial respiration as a source of cellular ROS $[110,111]$. Other factors involved in the development of oxidative stress in such circumstances include the oxidation of reduced glutathione (GSH), an increased $S$-nitrosylation of proteins and an increase in $\mathrm{Ca}^{2+}$ efflux from the ER into the mitochondria $[28,112]$. 


\section{Upregulation of PDI and Activation of NADPH Oxidase Isoforms}

The development of ER stress and activation of the UPR may lead to upregulation of PDI [113-116]. This is an important event in the context of the development of oxidative stress, as PDI is associated with NOX isoforms and acts as a redoxsensitive protein which regulates their activation $[10,109$, 117]. The change in cellular redox status "sensed" by PDI thus may activate NOX-2 and NOX-4 [10, 118, 119], leading to the production of superoxide ions $[120,121]$.

The effects of PDI in activating NOX enzymes appear to be of pathophysiological relevance since these enzymes are a major source of ROS in several cell types [122, 123], and ROS production by NOX isoforms may even exceed mitochondria as the prime source of ROS in some cell types [124]. However, while ROS production within mitochondria stems from the integral architecture and membrane organisation, NOX signalling is dependent on multiple protein interactions and post-translational modifications leading to the assembly of a functional NOX complex and the subsequent trafficking to specific subcellular locations $[122,123]$. The assembly of subunits and the translocation NOX enzymes to sites of activity appears to be met by the chaperone rather than the isomerase activity of PDI via hydrophobic rather than electrostatic or covalent associations [109, 125]. Nevertheless, both the chaperone and isomerase activities of PDI are required to fulfil its role in the oxidative folding of proteins within the ER [126].

\section{Upregulation of PDI and Increased Rate of ROS and RNS Production from Oxidative Protein Folding}

The ER contains numerous molecules whose task is to ensure that proteins secreted from the organelle have acquired the prerequisite post-translational modifications and the correct conformation [127]. One important process involved in ensuring optimal protein folding is the acquisition of disulphide bonds. The interaction between PDI and oxidoreductin- $1 \alpha$ $($ Erol $\alpha)$ is probably the most important vehicle for oxidative protein folding in the ER [128, 129]. Hence PDI has the capacity to supply, isomerise or, in some circumstances, reduce disulphide bonds in target proteins [130], while its activity is dependent upon the existence of two distinct remote active sites which are directly or indirectly oxidised by Ero $1 \alpha$ to form disulphide bridges [130-132]. Such oxidation provokes a conformational change allowing for the entry of unfolded protein substrates in the reduced state $[133,134]$. Once in situ, key thiol groups on these proteins are oxidised to form disulphide bridges, resulting in the reduction of PDI; these target proteins then "receive" disulphide bonds from PDI; Erol $\alpha$ then re-oxidises the reduced PDI and transfers electrons from the reduced PDI to molecular oxygen, which is subsequently reduced to hydrogen peroxide $\left(\mathrm{H}_{2} \mathrm{O}_{2}\right)[135,136]$, thus resulting in the re-oxidation of the oxidoreductase [128, 137]. The capacity of Ero1 $\alpha$ to reduce molecular oxygen is dependent on the existence of a helical structure containing flavin adenine dinucleotide (FAD) sealed by a disulphide bridge between Cys(208)-Cys(241). This "seal" may be disrupted via the formation of a mixed disulphide bridge between PDI and one of these cysteines, which underpins the capacity of this chaperone to regulate the activity of its cooxidoreductase $[135,136]$. In addition, Ero $1 \alpha$ activity in the ER is upregulated by the UPR and hence $\mathrm{H}_{2} \mathrm{O}_{2}$ levels may increase as a result of ER stress [135, 136]. Initially, such upregulation may have an adaptive purpose as the glutathione peroxidase isoform GPx7 may utilise $\mathrm{H}_{2} \mathrm{O}_{2}$ to accelerate the oxidative folding of substrates in vivo [65]. Briefly, evidence suggests that $\mathrm{H}_{2} \mathrm{O}_{2}$ oxidises the Cys 57 residue of GPx7 to produce sulfonic acid, which in turn may react with its Cys86 to form a disulphide bond. Both the disulphide and the sulfonic acid forms of GPx7 may oxidise PDI to catalyse oxidative folding [138]. However, the accumulation of ROS and reactive nitrogen species (RNS) following activation of the ER $[139,140]$ leads to $S$-nitrosylation and the subsequent inactivation of PDI, thus leading to a loss of its chaperone and isomerase activities [140-142]. This loss of activity may have meaningful pathophysiological consequences; the accumulation of misfolded proteins within the ER may further enhance the UPR, leading to self-amplifying increases in inflammation as well as oxidative and nitrosative stress [143, 144]. Importantly, such increases in ROS and RNS may also promote ER stress, which leads to an increase in $\mathrm{Ca}^{2+}$ efflux from the ER into mitochondria $[28,112]$ which is enabled by tubular channels tethering the organelles described as mitochondrial associated molecular membranes (MAMs) [5, 145]; an increase in $\mathrm{Ca}^{2+}$ within the mitochondria may ultimately lead to the development of multiple dimensions of mitochondrial dysfunction as discussed below.

\section{ER Stress, UPR Activation and Mitochondrial Dysfunction}

\section{Initial Increase in Mitochondrial Respiration}

The ER and mitochondria are physically connected by highly specialised structures referred to as MAMs. These molecules act as a conduit for the exchange of proteins, lipids, a range of metabolites, various signalling molecules and most importantly $\mathrm{Ca}^{2+}$, and this complex cascade of events appears to influence the balance between cell death and survival $[5,146]$. The architecture of a MAM is highly complex and contains a wide array of structural, functional and regulatory proteins, such as the GTPase activating protein for Rab32 [147, 148]. The inositol trisphosphate receptor (IP3R) and the voltage-dependent 
anion channels (VDACs) are among the most important molecules for enabling and regulating ER-mitochondria $\mathrm{Ca}^{2+}$ transfer, and are located in the ER and mitochondrial sides of MAMs, respectively, and may complex with the chaperone GRP75, thus forming a channel connecting the two organelles and enabling mutual exchange between membrane and luminal components [149, 150]. Mitofusin 2 (Mfn2) is another important protein present on the ER and mitochondrial surfaces, which plays an indispensable role in ER-mitochondria tethering as well as in the modulation of inter-mitochondrial contacts [5, 151, 152]. The composition of MAMs adapts in response to multiple internal and external stimuli $[153,154]$, while the formation or dissolution of contact areas between mitochondria and the ER is further regulated by other aspects of organelle dynamics [5, 148, 154]. Importantly, in the adaptive phase of ER stress, there is an increased number of physical contacts between the ER and mitochondrial networks at the perinuclear regions enabling increased transfer of $\mathrm{Ca}^{2+}$ from the ER into the mitochondria [5, 43, 146, 155].

An increase in $\mathrm{Ca}^{2+}$ uptake by the mitochondria may increase transmembrane potential and ATP production aimed at promoting cellular survival as part of an adaptive response to ER stress [156]. Such an increase in energy production is accompanied by increases in the production of mitochondrial proteases such as LON, which are induced by the activation of the PERK pathway, which in turn regulates the structural integrity and assembly of cytochrome $c$ oxidase (COX) [157, 158]. In this scenario, elevated expression of LON protease may increase mitochondrial performance by stimulating the assembly and increasing stabilisation of COX II [157, 158]. However, elevated calcium levels may also increase the production of ATP and ROS [159-161], leading to the activation of mitochondrial nitric oxide synthase (mtNOS) $[162,163]$, and the production of $\mathrm{NO}$, leading to the inhibition of mitochondrial function via a number of direct and indirect mechanisms including the reversible $S$-nitrosylation of key structural and functional mitochondrial proteins and enzymes [163-165].

Figure 3 summarises the effects of ER stress.

\section{Elevated Levels of NO and Mitochondrial Function}

The nitrosylation of mitochondrial structural proteins and enzymes may play a major role in the redox-based regulation of mitochondrial respiration [166, 167]. While nitrosylation in response to modest increases in NO levels may initially act as a defence mechanism aimed at maintaining protein structure and function [168-170], further increases in this RNS may lead to the inhibitory nitrosylation of crucial functional enzymes such as complex I of the electron transport chain $[165,171]$. Furthermore, the inhibition of complex I by $S$ nitrosylation is another initially cytoprotective response, which also leads to decreased ATP production and defects in

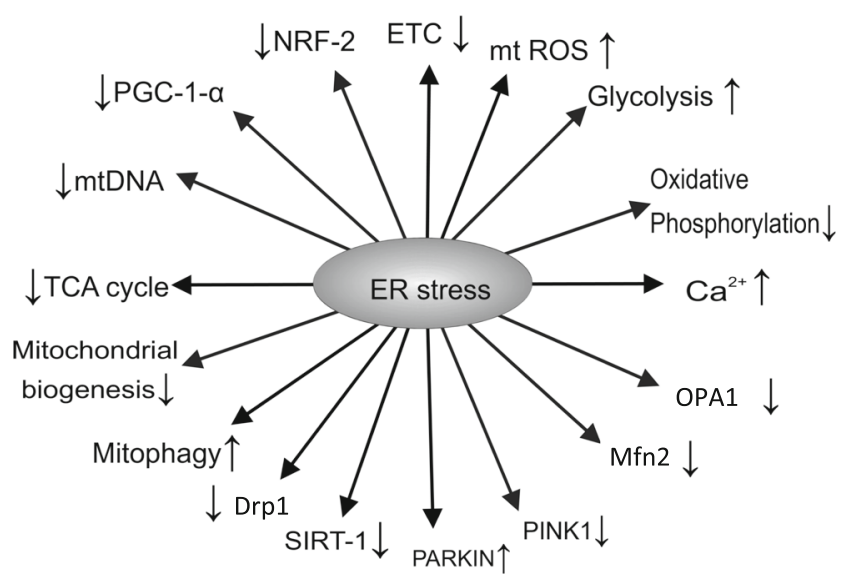

Fig. 3 Effects of ER stress

energy homoeostasis over time $[169,170]$. Persistently elevated cellular concentrations of NO may also lead to the inhibitory nitrosylation of crucial functional cysteine thiols of COX and complex II of the electron transport chain, thus leading to chronically suppressed activity of the former and transiently reduced activity of the latter $[172,173]$. Such inhibition may ultimately impair oxidative phosphorylation and hence decrease ATP production and GSH levels within the organelle [173-175]. Furthermore, the prolonged inhibition of COX activity also provokes an increase in ATP production via glycolysis in a wide range of cell types as a defensive response aimed at preventing apoptosis or necrosis [176-178]. Importantly, the inhibition of complex III and complex IV by $S$-nitrosylation may further increase the production of ROS [179, 180], which combined with reduced ATP generation may contribute to the release $\mathrm{Ca}^{2+}$ from the ER [181-183], which may further decrease the biosynthesis of ATP and also increase the generation of ROS in a positive feedback loop $[110,184]$. This process is of relevance, as an increased production of ROS may increase the misfolding of mitochondrial proteins, which coupled with impaired oxidative phosphorylation and ATP production may trigger another response aimed at restoring mitochondrial homoeostasis, namely the mitochondrial unfolded protein response (mtUPR) [185-188]. Thus, in the section below, we also discuss the putative pathophysiological relevance of the mtUPR.

\section{Impaired Mitochondrial Performance Following Activation of the mtUPR}

The mtUPR is a multidimensional transcriptional response initiated and maintained by retrograde mitochondrial-tonuclear signalling following increases in protein misfolding in the mitochondrial matrix and inner membrane space and/ or decreased efficiency of protein importation into mitochondria aimed at restoring mitochondrial function and preventing organellar death [189-192]. 
The initiation of the mtUPR is mediated by sensory quality control proteases with $\mathrm{LON}$ or $\mathrm{ClpCP}$ being the prime activators in the matrix [191] and the mitochondrial serine protease HTRA2 playing the same role at the inner membrane space [193-195]. Interestingly, the initial upregulation of HTRA2 is provoked by an overproduction of ROS and the subsequent phosphorylation of Akt, which in turn activates the oestrogen receptor in the outer mitochondrial membrane leading to upregulation of the transcription factor nuclear respiratory factor 1 (NRF-1) and ultimately leading to increased mitochondrial production of HTRA-2 [193]. This is an illustrative example of retrograde mitochondrion to nucleus signalling and is similar in principle to the retrograde ER to nucleus signalling that facilitates the UPR response (reviewed in [196]). Another example involves the upregulation of CHOP, which is an indispensable player in the regulation of mitochondrial proteases and chaperones, in an attempt to restore intra-mitochondrial protein folding homoeostasis [197, 198]. However, despite recent evidence suggesting that signals of protein unfolding within mitochondria are transduced to the nucleus via activation of c-Jun, JNK and the activator protein 1 (AP-1) [64, 191], thus sharing some characteristics with the ER UPR, the precise details underpinning this mechanism remain to be elucidated [190]. It should also be noted that while there is some evidence that the factors involved in initiating and regulating the mtUPR are similar in principle to those that regulate the ER UPR, there is another regulatory mechanism governing the mtUPR, namely decreased mitochondrial import efficiency, which is unique to the mtUPR, and some background information is required to understand its genesis and implications.

The vast majority of mitochondrial proteins originate from nuclear DNA and hence must be recruited to the mitochondria and thereafter imported. In most circumstances, this recruitment is initially achieved via the mitochondrial targeting sequence (MTS) [199]. Once in situ at the outer mitochondrial membrane $(\mathrm{OMM})$, the protein is directed via a myriad of regulatory processes to either the OMM, the intermembrane space, the inner mitochondrial membrane (IMM) or the matrix. Importantly, in order to enter the matrix, the protein must cross the IMM via the translocase of inner membrane complex (TIM), which requires the optimal activity of chaperones located at the matrix as well as physiological tricarboxylic acid (TCA) cycle and oxidative phosphorylation activities [199, 200]. Hence, mitochondrial protein import efficiency may provide a proxy measure of diverse aspects of mitochondrial performance [191, 201, 202]. Importantly, a lowered import of proteins into the mitochondria leads to the accumulation in the cytoplasm of proteins normally destined for the organelle [64, 203]. Most such proteins are detected and targeted for proteasomal degradation [204, 205]. However, in lower animals, at least one mitochondrial protein, the transcription factor ATFS-1, which regulates the mtUPR in the worm
Caenorhabditis elegans, has both a MTS, which enables its mitochondrial import in normal physiological conditions, and a nuclear localisation sequence (NLS), which enables its translocation to the nucleus in conditions of mitochondrial stress whereupon it activates the mtUPR [187]. There are excellent reviews detailing this process $[190,203]$. Notwithstanding that evidence of such a transcription factor in mammals is lacking, Fiorese et al. [206] have recently reported the existence of ATF5 in mammalian cells which is regulated similarly to ATFS-1 and may induce a similar transcriptional response.

The mtUPR is activated by a range of stressors other than the presence of unfolded proteins, which may lead to a decrease in mitochondrial protein import efficiency. In addition to the presence of heavy metals or other substances acting as DNA adducts, contaminants in sulphide bonds, or otherwise, such stressors include a depletion of mtDNA [186, 207], high levels of ROS [185, 186], mitochondrial ribosome impairment $[208,209]$, inhibition of mitochondrial proteases and chaperones [186], impaired oxidative phosphorylation and ATP production $[187,188]$ and abnormally high glucose consumption indicating a switch to the glycolytic pathway as a source of energy generation [210].

It should be stressed that while one facet of the mtUPR involves the upregulation of genes aimed at increasing mitochondrial proteases as well as chaperones, thereby promoting protein homoeostasis within the mitochondrial protein folding environment [186, 211], another facet includes changes in the transcription patterns of genes governing cellular metabolism [190]. In particular, the mtUPR may increase the expression of genes governing the rate of glycolysis and the catabolism of amino acids with a concomitant suppression of genes enabling the optimal performance of the TCA cycle and oxidative phosphorylation [212, 213].

Therefore, while aimed at relieving mitochondrial stress and ensuring cellular survival, the over- or chronic activation of the mtUPR may also compromise mitochondrial function and oxidative phosphorylation, thus favouring a switch to aerobic glycolysis as the predominant source of ATP $[212,213]$. These changes in cellular metabolism provoked by the activation of the mtUPR could be of interest given data demonstrating that such a response may be regulated by $\mathrm{NAD}^{+}$and sirtuin (SIRT) deacetylases [193, 209, 213], which are capable of sensing and stimulating metabolic activity by increasing mitochondrial performance via a number of different routes (reviewed by Morris et al. [214]). Importantly, SIRT-1 is inactivated in an environment of nitro-oxidative stress [215] and such inactivation may up-regulate NF-KB [215]. Hence, in a cellular environment of chronic oxidative stress the normal compensatory response to impaired mitochondrial function is negated and the switch to aerobic glycolysis via NF- $\mathrm{kB}$ upregulation is preferentially operating [216]. 
Furthermore, the progressive decline in mitochondrial ATP production and mitochondrial membrane potential in such circumstances coupled with an increase in aerobic glycolysis can activate another very specific mitochondrial quality control mechanism involving retrograde mitochondrion to nucleus signalling referred to as mitophagy $[217,218]$. Such a physiologically abnormal elevation in the rate of mitophagy has adverse bioenergetic consequences as this process appears to play a relevant role in the regulation of energy homoeostasis and mitochondrial dynamics [219, 220]. It is also noteworthy that ER stress and the UPR accompanied by increased levels of $\mathrm{Ca}^{2+}$ and ROS can also exert detrimental effects on multiple regulatory processes governing mitochondrial dynamics directly [221-223].

Key reactions and pathways associated with the mtUPR are summarised in Fig. 4.

\section{UPR Activation and Impaired Mitochondrial Dynamics}

\section{Background}

Accumulating evidence indicates that the balance of activity between pathways regulating mitophagy and those regulating mitochondrial dynamics (mitochondrial biogenesis, fusion, fission and motility) may influence mitochondrial mass, morphology and function and thus the cellular capacity to generate energy and to adjust energy production in the face of changing metabolic demands [219, 224, 225]. In particular, changes in mitochondrial dynamics enable these organelles to maintain a balance between energy production and changes in energy demand by generating highly fused networks of mitochondria or otherwise favouring the formation of more discrete and isolated organelles [226-228]. In addition, pathways and proteins governing mitochondrial dynamics may regulate energy supply and distribution at both the whole organism and cellular levels [229]. Therefore, the targeted manipulation of these processes may open a relevant therapeutic perspective for neuroprogressive disorders. Therefore, facets of mitochondrial dynamics as well as the pathophysiological influence of the chronic upregulation of the UPR on these processes will now be discussed as the final mechanistic section of this paper.

\section{ER Stress and UPR Activation as a Source of Impaired Mitochondrial Mitophagy}

Mitophagy is mediated by the cooperative action of the two proteins parkin and PINK. There are excellent reviews detailing the processes involved in the delivery and regulation of mitophagy $[203,219,225]$. Therefore, we provide a brief description of this process in order to explain the putative adverse effects of the UPR upon mitophagy.

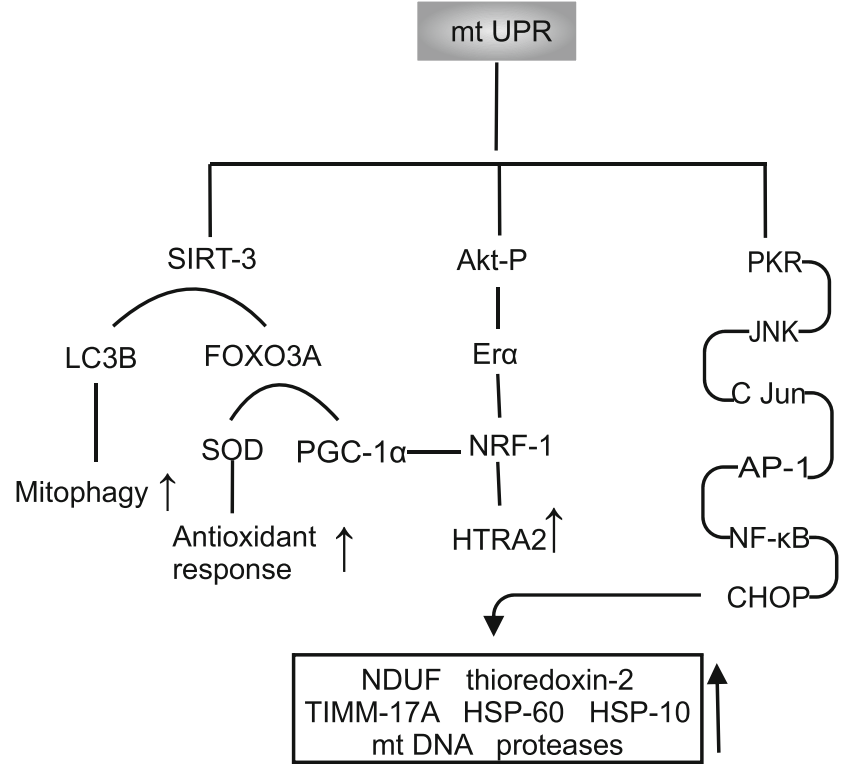

Fig. 4 Key reactions and pathways associated with the mtUPR

PINK1 is a serine/threonine kinase that possesses an $\mathrm{N}$ terminal mitochondria-targeting signal [230] enabling anchorage at the IMM. Under physiological conditions, PINK1 is imported into the mitochondria via TIM and translocase of outer membrane (TOM) protein complexes and is continuously degraded by PARL and matrix processing peptidase [230, 231]. However, following the accumulation of unfolded proteins and/or membrane depolarisation, mitochondrial import efficiency falls and therefore the import of PINK1 to the IMM is compromised [191, 201, 202]. Following such inhibition, the enzyme accumulates at the OMM and forms a large 700$\mathrm{kDa}$ complex with TOM before undergoing activation via autophosphorylation at two serine residues [232, 233]. This activation results in the recruitment of inactive cytosolic parkin onto damaged mitochondria, whereupon the molecule is activated via PINK1-mediated phosphorylation [234]. Following activation, parkin ubiquinates a myriad of mitochondrial substrates as well as itself [235]. These ubiquitinated residues in turn undergo phosphorylation, which is affected by PINK1, thereby triggering further cycles of parkin recruitment in a feed-forward amplification loop $[236,237]$. It should be noted that while this process is a prerequisite for the development of mitophagy, it is not sufficient in itself to precipitate the phenomenon, and other mechanisms also appear to play a role. Readers interested in a detailed account of such mechanisms are invited to consult previous work [238-240]. Moreover, mitophagy is also regulated by other processes governing mitochondrial dynamics [241-243], and an imbalance between mitophagy and mitochondrial biogenesis stemming from the activation of the UPR is now thought to play a relevant role in the pathophysiology of several neurodegenerative and neuroprogressive illnesses [225]. This is unsurprising given that the complex cross-talk 
between these processes is an essential element in regulating cellular energy homoeostasis [244, 245]. Importantly, changes in the rate of mitophagy may deregulate mitochondrial biogenesis $[219,246]$, thus compromising cellular energy homoeostasis.

\section{UPR Activation and Impaired Mitochondrial Biogenesis}

Under physiological conditions, mitochondrial biogenesis is regulated by a sophisticated interplay between the coactivator peroxisome proliferator-activated receptor gamma coactivator-1 alpha (PGC-1 $\alpha$ ) and the transcription factors NRF-2 and SIRT-1, which enable coupling between changes in cellular metabolism to changes in mitochondrial mass and number [34, 214, 247]. However, in an environment of ER stress and UPR activation, elevated levels of NF-KB, MAPK and $\mathrm{PKB} / \mathrm{Akt}$ as well as higher NO signalling provoke an increase in PGC-1 $\alpha$, NRF-1, NRF-2 and SIRT-1, which in turn induce an increase in mitochondrial biogenesis as a putative adaptive (i.e. pro-survival) response [248, 249]. However, with increasing levels of inflammation, and increased levels of oxidative and nitrosative stress, the upregulation of PGC- $1 \alpha$ is inhibited by TNF- $\alpha$ [104] and the activity of NRF-2, SIRT-1 and NF-KB may be inhibited by $S$-nitrosylation or overoxidation of cysteine residues which normally enable their function [171, 214], ultimately leading to a chronic state of decreased mitochondrial biogenesis. The processes governing mitochondrial biogenesis and those governing mitochondrial fusion and fission also engage in a complex bidirectional cross-talk which also plays a role in regulating cellular energy homoeostasis [250], and hence, impaired mitochondrial biogenesis can provoke adverse changes in processes governing mitochondrial fusion and fission which also have the effect of dysregulating cellular energy generation. In addition, the molecular players generating inflammation and oxidative stress also lead to compromised activity of proteins and pathways regulating fusion and fission, which may lead to decreased energy production at cellular and whole organism levels.

\section{UPR Activation and Impaired Activity of Proteins and Processes Governing Fusion and Fission}

\section{Background}

Mitochondrial fusion and fission processes are regulated and enabled by dynamin family GTPases [251]. Readers interested in a detailed explanation of the mechanisms underpinning the actions of these molecular motors are referred to the work of Ferguson and De Camilli [252]. In mammals, the fusion of OMMs is mediated by Mfn1 and Mfn2, whereas the fusion of inner membranes is mediated via the protein optic atrophy 1 (OPA1) [151, 253-256]. We will focus on their role in mitochondrial respiration and how their activities may be compromised in an environment of ER stress and chronic activation of the UPR.

\section{Role of Mitofusins in Energy Production and Consequences of UPR Upregulation}

Mfn2, and to a lesser extent Mfn1, plays pivotal roles in the regulation of mitochondrial respiration and energy homoeostasis [228, 257, 258]. This role is perhaps unsurprising given that $\mathrm{Mfn} 2$ is an indispensable player in tethering mitochondria and ER stress and enabling high fidelity and rapid calcium signalling cross-talk between the two organelles in environments of stress and changing metabolic demands for energy [259, 260]. While modulation of calcium signalling appears to be one element underpinning the capacity of $\mathrm{Mfn} 2$ to regulate mitochondrial respiration energy and adaptation to increased cellular demands for energy, other mechanisms are clearly involved. Such mechanisms involve the inhibition of ROS production and the regulation of glucose homoeostasis via mechanisms which are not related to effects on calcium signalling, although the precise details of such mechanisms remain to be fully delineated [257, 258]. Crucially, the capacity of this enzyme to adapt the production of ATP by hypothalamic neurones is a major factor in regulating whole body metabolism and whole body energy homoeostasis $[257,258]$. In this context, it is of paramount importance that the activity of this enzyme may be inhibited in an environment of chronic inflammation and nitrosative stress. For example, MAPK upregulation suppresses Mfn2 activity [261] and there is some evidence that this enzyme is inhibited in an environment in which the production of proinflammatory mediators is elevated [257]. It is also of interest that the capacity of Mfn2 to stimulate mitochondrial function is dependent on the activation of the PI3K/Akt pathway.

\section{Role of OPA1 in Energy Generation and Consequences of UPR Upregulation}

There is some evidence to suggest that processing of the mitochondrial dynamin-like GTPase OPA1 is the main regulatory element governing mitochondrial function by modulating IMM potential [262]. Several research teams investigating the effects of OPA1 mutants have adduced evidence indicating that OPA1 activity is an important factor determining the existence of cellular mitochondria as highly fused networks or a myriad of fragmented organelles, which affect the supply of ATP produced by oxidative phosphorylation and influence the capacity to increase cellular energy output in the face of increased metabolic demands for energy as discussed above $[263,264]$. These observations have been supported by recent 
in vitro data supplied by Kao and fellow workers who reported that inactivation of OPA 1 results in the fragmentation of established mitochondrial networks as well as a reduction in oxygen consumption, uncoupling of oxidative phosphorylation to ATP production and a shift to aerobic glycolysis as the main mode of energy generation [265].

OPA1 has several other regulatory roles in mitochondrial function such as maintaining the integrity of the quaternary structures of electron transport chain enzymes and preventing depolarisation of the IMM. In addition, OPA1-dependent stabilisation and remodelling of mitochondrial cristae increases the efficiency of energy production by the electron transport chain, while also reducing the production of ROS [266]. OPA1-driven cristae remodelling is another essential factor enabling cells to meet energy production in the context of enhanced energy demands [267]. The importance of OPA1 in this domain is further emphasised by the existence of data demonstrating that its targeted inactivation leads to detrimental changes in crista morphology and reduces the stability and performance of the electron transport chain, thereby compromising oxidative phosphorylation and ATP production $[268,269]$.

Other roles include stabilising the association between cardiolipin and COX, thereby acting as an anti-apoptotic protein [266, 268-270]. Perhaps predictably, there is experimental evidence that $O P A 1$ transcription and translation are upregulated in an environment of chronic nitro-oxidative stress [271], which is also supported by data demonstrating that mitochondrial dynamics in general, and OPA1 levels in particular, appear to be under the control of the non-canonical NF-KB pathway [272]. In addition, evidence indicates that levels of this enzyme are elevated following activation of the Akt/mTOR pathway [273] and more indirectly by ROS and $\mathrm{Ca}^{2+}$ and by upregulation of PGC- $1 \alpha$ [274]. The involvement of AKT and NF-KB in the regulation of OPA1 activity is particularly germane as both molecules are inactivated by $S$ nitrosylation in an environment of nitro-oxidative stress [275-278], and such inactivation may compromise the ability of mitochondria to cope with elevated cellular requirements for energy.

\section{The Role of Drp1 in Energy Generation and the Consequences of UPR Upregulation}

The activity of the mitochondrial fission protein Drp1 is regulated by a plethora of factors such as $\mathrm{Ca}^{2+}$ concentrations, ROS levels and a range of post-translational modifications [279-281] (see [282] for a review). Chronically elevated levels of ROS and RNS lead to changes in Drp1 activity and/or rates of mitochondrial fission via a number of routes. One such route involves the inactivation of Drp1 by AMPK, whose activity is upregulated in an environment of chronically elevated ROS generation [214, 283, 284]. This is of importance as there is evidence that inhibition of this GTPase may disrupt mitochondrial networks, thus leading to adverse changes in organelle morphology accompanied by a reduction in Mfn1 and Mfn2 as well as a compromised proteolytic processing of OPA1 isoforms [285] and hence presents yet another route by which the chronic upregulation of the UPR could compromise energy generation. It is also noteworthy that $S$-nitrosylation of Drp1 in an environment of chronically upregulated nitro-oxidative stress could increase the rate of mitochondrial fission [286], thereby creating an imbalance between fusion and fission which may lead to detrimental net alterations in mitochondrial morphology and energy production [287-289]. The precise mechanisms underpinning such an increase in fission rates is still a matter of ongoing debate. However, it may not be a direct consequence of nitrosylation-induced increases in the enzymatic activity of Drp1 [290]. Lastly, mitophagy relies on a synergistic interplay between parkin and the dynamin family kinase Drp1, with the fission activity of the latter required to generate small mitochondria, thereby enabling efficient engulfment by autophagosomes [239, 291]. Hence, inhibition of this enzyme may also lead to disrupted mitophagy, which in turn has the capacity to dysregulate mitochondrial dynamics, and ultimately ATP production, further compromising energy generation.

Having reviewed the multiple mechanisms involved in driving the advent or exacerbation of chronic inflammation, oxidative stress and mitochondrial dysfunction, we will now consider possible therapeutic targets for the management of neuroprogressive and neurodegenerative diseases. Based on the mechanisms highlighted, it seems reasonable to suggest that molecules with the capacity to target the mechanisms driving ER stress and the UPR and to ameliorate the adverse downstream events following the activation of these pathways, would be desirable, and this consideration forms the basis of the approaches suggested below.

\section{Possible Neurotherapeutic Targets}

\section{Melatonin}

Recent evidence indicates that melatonin exerts a regulatory role in the process of mitophagy by stimulating the autophagic clearance of irreparably damaged mitochondria and increasing mitochondrial biogenesis, probably by a route involving the activation of AMPK and SIRT-1 [292-294]. Melatonin administration may also restore calcium homoeostasis, mitochondrial dynamics and mitochondrial permeability transition [295-298]. At least partly, those beneficial effects appear to be related to entry into the organelle, which may be facilitated by Glut-1 or peptide 1 and 2 transporter proteins located in the OMM [299, 300]. 
Moreover, melatonin may shift the pattern of mitochondrial dynamics towards a decrease in fission and an increase in fusion [296, 298, 301]. This activity has been demonstrated in a wide range of cell types [297, 301]. From a mechanistic perspective, the weight of evidence suggests that melatonin may attenuate the translocation of Fis1, Drp1 and Bax from the cytosol to mitochondria and may also upregulate mitochondrial fusion proteins Mfn1, Mfn2 and OPA1 [295, 300, 302, 303].

Melatonin supplementation also exerts multiple protective effects on mitochondria via a number of different mechanisms which may mitigate against the development of maladaptive processes within these organelles which initially stem from the upregulation of the UPR (i.e. ER stress). Such mechanisms include a reduction of mitochondrial oxidative stress [304, 305]; an increased efficiency of ATP production [306, 307]; a reduction in mitochondrial NOS expression [308, 309]; an amelioration of calcium dyshomoeostasis [310, 311]; the preservation of mitochondrial membrane potential [307, 312]; and a reduced release of cytochrome $c$ into the cytosol accompanied by the inhibition of caspase-3 activity [313]. Several authors have demonstrated protective effects of melatonin supplementation against damage to mitochondria caused by a myriad of different insults including, but not limited to, sepsis [314, 315], ischaemia/reperfusion [316, 317] and challenge with neurotoxic compounds such as 1-methyl-4phenylpyridinium ion $\left(\mathrm{MPP}^{+}\right)$[302], $\beta$-amyloid peptide $(\mathrm{A} \beta$ 25-35) [318, 319], 4-hydroxynonenal [320] and lipopolysaccharide [309].

Melatonin therapy also inhibits the DNA binding activity and activation of NF-KB, with concomitant reductions in NLRP3 activity and the synthesis of pro-inflammatory cytokines [321-323]. These anti-inflammatory effects are considered to underpin the promising results obtained from studies investigating the use of melatonin in animal models of neurodegenerative diseases and are the motivation for an increased focus on the use of the molecule as a therapeutic agent targeting the pathogenesis and pathophysiology of diseases such as Alzheimer's disease and Parkinson's disease at doses ranging from 50 to $100 \mathrm{mg}$ daily $[305,324]$. In addition, it has been proposed that melatonin treatment could be useful for cognitive dysfunction associated with mood disorders [325]. However, evidence remains inconclusive [326].

\section{$\mathrm{CoQ}_{10}$}

Converging preclinical and clinical evidence suggest that coenzyme $\mathrm{Q}_{10}\left(\mathrm{CoQ}_{10}\right)$ supplementation may offer therapeutic benefits in a range of neurodegenerative and neuroprogressive disorders, at least partly owing to its effects on ER stress and adverse downstream effects. For example, Yubero-Serrano et al. [327] reported that supplementation of $\mathrm{CoQ}_{10}$ in tandem with a Mediterranean diet effectively suppressed the expression of genes encoding proteins involved in the UPR. Furthermore, $\mathrm{CoQ}_{10}$ also appeared to exert a positive effect on mitochondrial dynamics by exerting a direct effect on ATP production [328], while this therapeutic target may also preserve the structure of mitochondrial cristae, with an accompanying increase in mitochondrial biogenesis [329]. In addition, $\mathrm{CoQ}_{10}$ may also restore endogenous anti-oxidants, such as vitamin E [330], and is also an essential player in enabling the optimal performance of the electron transport chain and stabilisation of the mitochondrial permeability transition pore [331] (reviewed by [332]).

There is also a considerable and increasing body of evidence demonstrating beneficial effects of $\mathrm{CoQ}_{10}$ on levels of pro-inflammatory cytokines and ROS, which may both act as a trigger of the UPR and be effectors of pathology following activation. For example, the effectiveness of $\mathrm{CoQ}_{10}$ supplementation at a daily dose of $500 \mathrm{mg}$ for 12 weeks reduced inflammation and oxidative stress in a randomised, doubleblind, placebo-controlled trial involving participants with relapsing-remitting multiple sclerosis [333, 334]. Controlled data demonstrating the ameliorative effects on inflammation and oxidative stress of $\mathrm{CoQ}_{10}$ supplementation also extend into other disease areas such as coronary artery disease, and there is some evidence that such benefits could be dose related [335]. In addition, evidence suggests that $\mathrm{CoQ}_{10}$ supplementation at doses up to $300 \mathrm{mg} /$ day is safe and well tolerated [336, 337]. The former research team reported a significant reduction in cardiovascular mortality, over and above that seen in patients receiving standard treatment, in an elderly population of 445 patients supplemented with $200 \mathrm{mg}$ of $\mathrm{CoQ}_{10}$ for 4 years [336], while the latter group of researchers found a significant reduction in cardiovascular morbidity and mortality in a population of 420 patients with chronic heart failure supplemented with $300 \mathrm{mg}$ of CoQ ${ }_{10}$ for 2 years [337]. Human and animal studies have also demonstrated the potential for increased clinical benefit from the use of mitochondrial-targeted $\mathrm{CoQ}_{10}$ (MitoQ) where the active molecule is covalently attached to the lipophilic triphenylphosphonium cation [300, 338]. This mode of delivery allows levels of $\mathrm{CoQ}_{10}$ to accumulate within the mitochondrial matrix, reaching levels several hundred-fold higher than can be achieved via supplementation with the naked coenzyme [338, 339]. Human trials of the use of MitoQ in the treatment of neurodegenerative diseases have produced initial evidence of benefit with particularly encouraging results seen in Parkinson's disease [340, 341]. In addition, $\mathrm{CoQ}_{10}$ could represent a novel therapeutic target for cognitive dysfunction associated with mood disorders [342], and a recent uncontrolled study found potential benefits for $\mathrm{CoQ}_{10}$ as a treatment for bipolar depression in late-life [343]. Clearly, the field awaits the design of large-scale and well-designed controlled trials testing $\mathrm{CoQ}_{10}$ as a therapeutic target for mood disorders. 


\section{NAC}

Animal and clinical studies have reported beneficial effects of $\mathrm{N}$-acetylcysteine (NAC) supplementation on levels of ER stress [344-347]. For example, rats supplemented for 2 months with drinking water containing $600 \mathrm{mg}$ NAC per litre displayed reduced levels of PDI and GRP78 compared with rats which did not receive NAC [345]. Similar findings indicate that NAC supplementation at 100 or $300 \mathrm{mg} / \mathrm{kg}$ for 20 weeks promote significant reductions in ROS levels [346, 347]. Moreover, NAC-related benefits upon ER stress appear to be dose-dependent, with $20 \mathrm{mmol} / \mathrm{L}$ of NAC being more effective than $10 \mathrm{mmol} / \mathrm{L}$ in reducing levels of GRP78 and ROS [348]. It should be noted, however, that NAC is a pleiotropic agent and several mechanisms other than direct effects on the UPR may also contribute to its therapeutic effects across neurodegenerative and neuroprogressive diseases $[349,350]$, while evidence suggests that adjunctive NAC treatment may mitigate cognitive dysfunction in a range of such disorders [351].

\section{Conclusions and Future Directions}

This review indicates that pathways related to the UPR may reciprocally interact with immune-inflammatory, neuro-oxidative, neuro-nitrosative, as well as mitochondrial mechanisms, which are thought to play a major shared pathophysiological role across several neuroprogressive and neurodegenerative diseases. Therefore, the chronic upregulation of the UPR may interact with a range of cell death mechanisms underpinning neurodegeneration and neuroprogression [352] and hence represents a novel neurotherapeutic target.

Moreover, this review also opens relevant directions for further research. First, the involvement of mechanistic pathways related to the UPR in separate disorders deserves further investigation. Second, the extent to which effects upon the UPR could contribute to therapeutic benefits of novel therapeutic targets (for example, melatonin, $\mathrm{CoQ}_{10}$ and NAC) is a matter of ongoing research efforts. Lastly, the identification of patients who could benefit from therapies targeting ER stress pathways, taking in account the emerging framework of precision psychiatry [353], could represent a relevant road of research.

Acknowledgements We should like to thank Myrela O. Machado, MD, $\mathrm{PhD}$, for her kind assistance with the figures.

Authorships All authors contributed to the writing up of the paper.

\section{Compliance with Ethical Standards}

Conflict of Interest The authors declare that they have no conflicts of interest.
Open Access This article is distributed under the terms of the Creative Commons Attribution 4.0 International License (http:// creativecommons.org/licenses/by/4.0/), which permits unrestricted use, distribution, and reproduction in any medium, provided you give appropriate credit to the original author(s) and the source, provide a link to the Creative Commons license, and indicate if changes were made.

\section{References}

1. Schroder M (2008) Endoplasmic reticulum stress responses. Cell Mol Life Sci 65(6):862-894. https://doi.org/10.1007/s00018-0077383-5

2. Lindholm D, Wootz H, Korhonen L (2006) ER stress and neurodegenerative diseases. Cell Death Differ 13(3):385-392. https:// doi.org/10.1038/sj.cdd.4401778

3. Görlach A, Klappa P, Kietzmann DT (2006) The endoplasmic reticulum: folding, calcium homeostasis, signaling, and redox control. Antioxid Redox Signal 8(9-10):1391-1418. https://doi. org/10.1089/ars.2006.8.1391

4. Fedoroff N (2006) Redox regulatory mechanisms in cellular stress responses. Ann Bot 98(2):289-300. https://doi.org/10.1093/aob/ $\operatorname{mcl} 128$

5. Marchi S, Patergnani S, Pinton P (2014) The endoplasmic reticulum-mitochondria connection: one touch, multiple functions. Biochim Biophys Acta 1837(4):461-469. https://doi.org/10. 1016/j.bbabio.2013.10.015

6. Torres-Peraza JF, Engel T, Martin-Ibanez R, Sanz-Rodriguez A, Fernandez-Fernandez MR, Esgleas M, Canals JM, Henshall DC et al (2013) Protective neuronal induction of ATF5 in endoplasmic reticulum stress induced by status epilepticus. Brain 136(Pt 4): 1161-1176. https://doi.org/10.1093/brain/awt044

7. Hetz C (2012) The unfolded protein response: controlling cell fate decisions under ER stress and beyond. Nat Rev Mol Cell Biol 13(2):89-102

8. Cheng Y, Yang JM (2011) Survival and death of endoplasmicreticulum-stressed cells: role of autophagy. World J Biol Chem 2(10):226-231. https://doi.org/10.4331/wjbc.v2.i10.226

9. Benbrook DM, Long A (2012) Integration of autophagy, proteasomal degradation, unfolded protein response and apoptosis. Exp Oncol 34(3):286-297

10. Laurindo FR, Fernandes DC, Amanso AM, Lopes LR, Santos CX (2008) Novel role of protein disulfide isomerase in the regulation of NADPH oxidase activity: pathophysiological implications in vascular diseases. Antioxid Redox Signal 10(6):1101-1113. https://doi.org/10.1089/ars.2007.2011

11. Santos CX, Tanaka LY, Wosniak J, Laurindo FR (2009) Mechanisms and implications of reactive oxygen species generation during the unfolded protein response: roles of endoplasmic reticulum oxidoreductases, mitochondrial electron transport, and NADPH oxidase. Antioxid Redox Signal 11(10):2409-2427. https://doi.org/10.1089/ars.2009.2625

12. Pfaffenseller B, Wollenhaupt-Aguiar B, Fries GR, Colpo GD, Burque RK, Bristot G, Ferrari P, Ceresér KMM et al (2014) Impaired endoplasmic reticulum stress response in bipolar disorder: cellular evidence of illness progression. Int $\mathrm{J}$ Neuropsychopharmacol 17(09):1453-1463. https://doi.org/10. 1017/s1461145714000443

13. Salminen A, Kauppinen A, Suuronen T, Kaarniranta K, Ojala J (2009) ER stress in Alzheimer's disease: a novel neuronal trigger for inflammation and Alzheimer's pathology. J Neuroinflammation 6:41. https://doi.org/10.1186/1742-2094-6-41 
14. Viana RJ, Nunes AF, Rodrigues CM (2012) Endoplasmic reticulum enrollment in Alzheimer's disease. Mol Neurobiol 46(2):522 534. https://doi.org/10.1007/s12035-012-8301-x

15. Wang HQ, Takahashi R (2007) Expanding insights on the involvement of endoplasmic reticulum stress in Parkinson's disease. Antioxid Redox Signal 9(5):553-561. https://doi.org/10.1089/ ars.2006.1524

16. Cali T, Ottolini D, Brini M (2011) Mitochondria, calcium, and endoplasmic reticulum stress in Parkinson's disease. Biofactors 37(3):228-240. https://doi.org/10.1002/biof.159

17. Stone S, Lin W (2015) The unfolded protein response in multiple sclerosis. Front Neurosci 9:264. https://doi.org/10.3389/fnins. 2015.00264

18. Getts MT, Getts DR, Kohm AP, Miller SD (2008) Endoplasmic reticulum stress response as a potential therapeutic target in multiple sclerosis. Therapy 5(5):631-640. https://doi.org/10.2217/ 14750708.5.5.631

19. Lautenschlaeger J, Prell T, Grosskreutz J (2012) Endoplasmic reticulum stress and the ER mitochondrial calcium cycle in amyotrophic lateral sclerosis. Amyotroph Lateral Scler 13(2):166-177. https://doi.org/10.3109/17482968.2011.641569

20. Tadic V, Prell T, Lautenschlaeger J, Grosskreutz J (2014) The ER mitochondria calcium cycle and ER stress response as therapeutic targets in amyotrophic lateral sclerosis. Front Cell Neurosci 8:147. https://doi.org/10.3389/fncel.2014.00147

21. Hayashi A, Kasahara T, Kametani M, Toyota T, Yoshikawa T, Kato T (2008) Aberrant endoplasmic reticulum stress response in lymphoblastoid cells from patients with bipolar disorder. Int $\mathrm{J}$ Neuropsychopharmacol 12(01):33. https://doi.org/10.1017/ s1461145708009358

22. Bengesser SA, Fuchs R, Lackner N, Birner A, Reininghaus B, Meier-Allard N, Stracke A, Kapfhammer HP et al (2016) Endoplasmic reticulum stress and bipolar disorder-almost forgotten therapeutic drug targets in the unfolded protein response pathway revisited. CNS Neurol Disord Drug Targets 15(4):403413

23. Gold PW, Licinio J, Pavlatou MG (2013) Pathological parainflammation and endoplasmic reticulum stress in depression: potential translational targets through the CNS insulin, klotho and PPAR-[gamma] systems. Mol Psychiatry 18(2):154165

24. Timberlake MA, Dwivedi Y (2015) Altered expression of endoplasmic reticulum stress associated genes in hippocampus of learned helpless rats: relevance to depression pathophysiology. Front Pharmacol 6:319. https://doi.org/10.3389/fphar.2015.00319

25. Rubio MD, Wood K, Haroutunian V, Meador-Woodruff JH (2013) Dysfunction of the ubiquitin proteasome and ubiquitin-like systems in schizophrenia. Neuropsychopharmacology 38(10):1910 1920. https://doi.org/10.1038/npp.2013.84

26. Grootjans J, Kaser A, Kaufman RJ, Blumberg RS (2016) The unfolded protein response in immunity and inflammation. Nat Rev Immunol 16(8):469-484. https://doi.org/10.1038/nri.2016.62

27. Garg AD, Kaczmarek A, Krysko O, Vandenabeele P, Krysko DV, Agostinis P (2012) ER stress-induced inflammation: does it aid or impede disease progression? Trends Mol Med 18(10):589-598. https://doi.org/10.1016/j.molmed.2012.06.010

28. Eletto D, Chevet E, Argon Y, Appenzeller-Herzog C (2014) Redox controls UPR to control redox. J Cell Sci 127(Pt 17): 3649-3658. https://doi.org/10.1242/jcs. 153643

29. Cao SS, Kaufman RJ (2013) Targeting endoplasmic reticulum stress in metabolic disease. Expert Opin Ther Targets 17(4):437448. https://doi.org/10.1517/14728222.2013.756471

30. Rocha M, Diaz-Morales N, Rovira-Llopis S, Escribano-Lopez I, Banuls C, Hernandez-Mijares A, Diamanti-Kandarakis E, Victor VM (2016) Mitochondrial dysfunction and endoplasmic reticulum stress in diabetes. Curr Pharm Des 22(18):2640-2649
31. Morais KL, Pacheco MT, Berra CM, Bosch RV, Sciani JM, Chammas R, de Freitas SR, Iqbal A et al (2016) Amblyomin-X induces ER stress, mitochondrial dysfunction, and caspase activation in human melanoma and pancreatic tumor cell. Mol Cell Biochem 415(1-2):119-131. https://doi.org/10.1007/s11010016-2683-4

32. Grimm S (2012) The ER-mitochondria interface: the social network of cell death. Biochim Biophys Acta 1823(2):327-334. https://doi.org/10.1016/j.bbamcr.2011.11.018

33. Scaini G, Rezin GT, Carvalho AF, Streck EL, Berk M, Quevedo J (2016) Mitochondrial dysfunction in bipolar disorder: evidence, pathophysiology and translational implications. Neurosci Biobehav Rev 68:694-713. https://doi.org/10.1016/j.neubiorev. 2016.06.040

34. Morris G, Berk M (2015) The many roads to mitochondrial dysfunction in neuroimmune and neuropsychiatric disorders. BMC Med 13(1):68

35. Moylan S, Maes M, Wray NR, Berk M (2013) The neuroprogressive nature of major depressive disorder: pathways to disease evolution and resistance, and therapeutic implications. Mol Psychiatry 18(5):595-606. https://doi.org/10.1038/mp.2012. 33

36. Bhat AH, Dar KB, Anees S, Zargar MA, Masood A, Sofi MA, Ganie SA (2015) Oxidative stress, mitochondrial dysfunction and neurodegenerative diseases; a mechanistic insight. Biomed Pharmacother 74:101-110. https://doi.org/10.1016/j.biopha. 2015.07.025

37. Kohler CA, Freitas TH, Maes M, de Andrade NQ, Liu CS, Fernandes BS, Stubbs B, Solmi M et al (2017) Peripheral cytokine and chemokine alterations in depression: a meta-analysis of 82 studies. Acta Psychiatr Scand 135(5):373-387. https://doi.org/ 10.1111/acps. 12698

38. Lai KSP, Liu CS, Rau A, Lanctot KL, Kohler CA, Pakosh M, Carvalho AF, Herrmann N (2017) Peripheral inflammatory markers in Alzheimer's disease: a systematic review and metaanalysis of 175 studies. J Neurol Neurosurg Psychiatry 88(10): 876-882. https://doi.org/10.1136/jnnp-2017-316201

39. Kohler CA, Freitas TH, Stubbs B, Maes M, Solmi M, Veronese N, de Andrade NQ, Morris G et al (2017) Peripheral alterations in cytokine and chemokine levels after antidepressant drug treatment for major depressive disorder: systematic review and meta-analysis. Mol Neurobiol. https://doi.org/10.1007/s12035-017-0632-1

40. Qi X, Hosoi T, Okuma Y, Kaneko M, Nomura Y (2004) Sodium 4-phenylbutyrate protects against cerebral ischemic injury. Mol Pharmacol 66(4):899-908. https://doi.org/10.1124/mol.104. 001339

41. Sokka AL, Putkonen N, Mudo G, Pryazhnikov E, Reijonen S, Khiroug L, Belluardo N, Lindholm D et al (2007) Endoplasmic reticulum stress inhibition protects against excitotoxic neuronal injury in the rat brain. J Neurosci 27(4):901-908. https://doi.org/ 10.1523/jneurosci.4289-06.2007

42. Maly DJ, Papa FR (2014) Druggable sensors of the unfolded protein response. Nat Chem Biol 10(11):892-901. https://doi. org/10.1038/nchembio.1664

43. Bravo R, Gutierrez T, Paredes F, Gatica D, Rodriguez AE, Pedrozo Z, Chiong M, Parra V et al (2012) Endoplasmic reticulum: ER stress regulates mitochondrial bioenergetics. Int $\mathrm{J}$ Biochem Cell Biol 44(1):16-20. https://doi.org/10.1016/j.biocel. 2011.10.012

44. Wang M, Wey S, Zhang Y, Ye R, Lee AS (2009) Role of the unfolded protein response regulator GRP78/BiP in development, cancer, and neurological disorders. Antioxid Redox Signal 11(9): 2307-2316. https://doi.org/10.1089/ars.2009.2485

45. Bertolotti A, Zhang Y, Hendershot LM, Harding HP, Ron D (2000) Dynamic interaction of BiP and ER stress transducers in 
the unfolded-protein response. Nat Cell Biol 2(6):326-332. https://doi.org/10.1038/35014014

46. Harding HP, Zhang Y, Bertolotti A, Zeng H, Ron D (2000) Perk is essential for translational regulation and cell survival during the unfolded protein response. Mol Cell 5(5):897-904

47. Lenna S, Trojanowska M (2012) The role of endoplasmic reticulum stress and the unfolded protein response in fibrosis. Curr Opin Rheumatol 24 (6). doi:https://doi.org/10.1097/BOR. 0b013e3283588dbb

48. Lu M, Lawrence DA, Marsters S, Acosta-Alvear D, Kimmig P, Mendez AS, Paton AW, Paton JC et al (2014) Opposing unfoldedprotein-response signals converge on death receptor 5 to control apoptosis. Science 345(6192):98-101. https://doi.org/10.1126/ science. 1254312

49. Meares GP, Liu Y, Rajbhandari R, Qin H, Nozell SE, Mobley JA, Corbett JA, Benveniste EN (2014) PERK-dependent activation of JAK1 and STAT3 contributes to endoplasmic reticulum stressinduced inflammation. Mol Cell Biol 34(20):3911-3925. https:// doi.org/10.1128/mcb.00980-14

50. Kolattukudy PE, Niu J (2012) Inflammation, endoplasmic reticulum stress, autophagy, and the monocyte chemoattractant protein1/CCR2 pathway. Circul Res 110(1):174-189. https://doi.org/10. 1161/circresaha.111.243212

51. Bobrovnikova-Marjon E, Grigoriadou C, Pytel D, Zhang F, Ye J, Koumenis C, Cavener D, Diehl JA (2010) PERK promotes cancer cell proliferation and tumor growth by limiting oxidative DNA damage. Oncogene 29(27):3881-3895 http://www.nature.com/ onc/journal/v29/n27/suppinfo/onc2010153s1.html

52. Cullinan SB, Diehl JA (2004) PERK-dependent activation of Nrf2 contributes to redox homeostasis and cell survival following endoplasmic reticulum stress. J Biol Chem 279(19):20108-20117. https://doi.org/10.1074/jbc.M314219200

53. Cullinan SB, Zhang D, Hannink M, Arvisais E, Kaufman RJ, Diehl JA (2003) Nrf2 is a direct PERK substrate and effector of PERK-dependent cell survival. Mol Cell Biol 23(20):7198-7209. https://doi.org/10.1128/MCB.23.20.7198-7209.2003

54. Yamasaki-Mann M, Demuro A, Parker I (2010) Modulation of endoplasmic reticulum $\mathrm{Ca} 2+$ store filling by cyclic ADP-ribose promotes inositol trisphosphate (IP3)-evoked Ca2+ signals. J Biol Chem 285(32):25053-25061. https://doi.org/10.1074/jbc. m109.095257

55. Rao J, Yue S, Fu Y, Zhu J, Wang X, Busuttil RW, KupiecWeglinski JW, Lu L et al (2014) ATF6 mediates a proinflammatory synergy between ER stress and TLR activation in the pathogenesis of liver ischemia reperfusion injury. Am J Transplant Off J Am Soc Transplant Am Soc Transplant Surg 14(7):1552-1561. https://doi.org/10.1111/ajt.12711

56. Walter P, Ron D (2011) The unfolded protein response: from stress pathway to homeostatic regulation. Science 334(6059):10811086. https://doi.org/10.1126/science.1209038

57. Lee J, Ozcan U (2014) Unfolded protein response signaling and metabolic diseases. J Biol Chem 289(3):1203-1211. https://doi. org/10.1074/jbc.R113.534743

58. Lee AH, Iwakoshi NN, Glimcher LH (2003) XBP-1 regulates a subset of endoplasmic reticulum resident chaperone genes in the unfolded protein response. Mol Cell Biol 23(21):7448-7459

59. Xiang C, Wang Y, Zhang H, Han F (2017) The role of endoplasmic reticulum stress in neurodegenerative disease. Apoptosis 22(1):1-26. https://doi.org/10.1007/s10495-016-1296-4

60. Sano R, Reed JC (2013) ER stress-induced cell death mechanisms. Biochim Biophys Acta 1833(12):3460-3470. https://doi. org/10.1016/j.bbamcr.2013.06.028

61. Darling NJ, Cook SJ (2014) The role of MAPK signalling pathways in the response to endoplasmic reticulum stress. Biochim Biophys Acta 1843(10):2150-2163. https://doi.org/10.1016/j. bbamcr.2014.01.009
62. Clarke R, Cook K (2015) Unfolding the role of stress response signaling in endocrine resistant breast cancers. Front Oncol 5(140). https://doi.org/10.3389/fonc.2015.00140

63. Janssens S, Pulendran B, Lambrecht BN (2014) Emerging functions of the unfolded protein response in immunity. Nat Immunol 15(10):910-919. https://doi.org/10.1038/ni.2991

64. Jovaisaite V, Auwerx J (2015) The mitochondrial unfolded protein response-synchronizing genomes. Curr Opin Cell Biol 33:74-81. https://doi.org/10.1016/j.ceb.2014.12.003

65. Wang M, Kaufman RJ (2014) The impact of the endoplasmic reticulum protein-folding environment on cancer development. Nat Rev Cancer 14(9):581-597. https://doi.org/10.1038/nrc3800 http://www.nature.com/nrc/journal/v14/n9/abs/nrc3800.html\# supplementary-information

66. Song L, De Sarno P, Jope RS (2002) Central role of glycogen synthase kinase- $3 \beta$ in endoplasmic reticulum stress-induced caspase-3 activation. J Biol Chem 277(47):44701-44708. https://doi. org/10.1074/jbc.M206047200

67. Qin L, Wang Z, Tao L, Wang Y (2010) ER stress negatively regulates AKT/TSC/mTOR pathway to enhance autophagy. Autophagy 6(2):239-247

68. Kapuy O, Vinod PK, Bánhegyi G (2014) mTOR inhibition increases cell viability via autophagy induction during endoplasmic reticulum stress - an experimental and modeling study. FEBS Open Bio 4:704-713. https://doi.org/10.1016/j.fob.2014.07.006

69. Qu M, Shen W (2015) Role of PI3K/Akt pathway in endoplasmic reticulum stress and apoptosis induced by saturated fatty acid in human steatotic hepatocytes. Zhonghua gan zang bing za zhi $=$ Zhonghua ganzangbing zazhi $=$ Chinese Journal of Hepatology 23(3):194-199. https://doi.org/10.3760/cma.j.issn.1007-3418. 2015.03.008

70. Mantuano E, Henry K, Yamauchi T, Hiramatsu N, Yamauchi K, Orita S, Takahashi K, Lin JH et al (2011) The unfolded protein response is a major mechanism by which LRP1 regulates Schwann cell survival after injury. J Neurosci 31(38):1337613385. https://doi.org/10.1523/JNEUROSCI.2850-11.2011

71. Hao F, Yang C, Chen SS, Wang YY, Zhou W, Hao Q, Lu T, Hoffer B et al (2017) Long-term protective effects of AAV9mesencephalic astrocyte-derived neurotrophic factor gene transfer in parkinsonian rats. Exp Neurol 291:120-133. https://doi.org/10. 1016/j.expneurol.2017.01.008

72. Nivon M, Fort L, Muller P, Richet E, Simon S, Guey B, Fournier M, Arrigo AP et al (2016) NFkappaB is a central regulator of protein quality control in response to protein aggregation stresses via autophagy modulation. Mol Biol Cell 27(11):1712-1727. https://doi.org/10.1091/mbc.E15-12-0835

73. Wang X, Shao Z, Zetoune FS, Zeidler MG, Gowrishankar K, Vincenz C (2003) NRADD, a novel membrane protein with a death domain involved in mediating apoptosis in response to ER stress. Cell Death Differ 10(5):580-591. https://doi.org/10.1038/ sj.cdd. 4401208

74. Homma K, Katagiri K, Nishitoh H, Ichijo H (2009) Targeting ASK1 in ER stress-related neurodegenerative diseases. Expert Opin Ther Targets 13(6):653-664. https://doi.org/10.1517/ 14728220902980249

75. Walter F, Schmid J, Dussmann H, Concannon CG, Prehn JH (2015) Imaging of single cell responses to ER stress indicates that the relative dynamics of IRE1/XBP1 and PERK/ATF4 signalling rather than a switch between signalling branches determine cell survival. Cell Death Differ 22(9):1502-1516. https://doi.org/10. 1038/cdd.2014.241

76. Sekine Y, Takeda K, Ichijo H (2006) The ASK1-MAP kinase signaling in ER stress and neurodegenerative diseases. Curr Mol Med 6(1):87-97

77. Meares GP, Mines MA, Beurel E, Eom TY, Song L, Zmijewska AA, Jope RS (2011) Glycogen synthase kinase-3 regulates 
endoplasmic reticulum (ER) stress-induced CHOP expression in neuronal cells. Exp Cell Res 317(11):1621-1628. https://doi.org/ 10.1016/j.yexcr.2011.02.012

78. Camacho A, Rodriguez-Cuenca S, Blount M, Prieur X, Barbarroja N, Fuller M, Hardingham GE, Vidal-Puig A (2012) Ablation of PGC1 beta prevents mTOR dependent endoplasmic reticulum stress response. Exp Neurol 237(2):396-406. https://doi.org/10. 1016/j.expneurol.2012.06.031

79. Abelaira HM, Reus GZ, Ignacio ZM, Dos Santos MA, de Moura AB, Matos D, Demo JP, da Silva JB et al (2017) Effects of ketamine administration on mTOR and reticulum stress signaling pathways in the brain after the infusion of rapamycin into prefrontal cortex. J Psychiatr Res 87:81-87. https://doi.org/10.1016/j. jpsychires.2016.12.002

80. Abelaira HM, Reus GZ, Ignacio ZM, Dos Santos MAB, de Moura AB, Matos D, Demo JP, da Silva JBI et al (2017) Ketamine exhibits different neuroanatomical profile after mammalian target of rapamycin inhibition in the prefrontal cortex: the role of inflammation and oxidative stress. Mol Neurobiol 54(7):5335-5346. https://doi.org/10.1007/s12035-016-0071-4

81. Gardner BM, Pincus D, Gotthardt K, Gallagher CM, Walter P (2013) Endoplasmic reticulum stress sensing in the unfolded protein response. Cold Spring Harb Perspect Biol 5(3):a013169. https://doi.org/10.1101/cshperspect.a013169

82. Pereira CFM (2013) Crosstalk between endoplasmic reticulum stress and protein misfolding in neurodegenerative diseases. ISRN Cell Biol 2013:22. https://doi.org/10.1155/2013/256404

83. Li M, Georgakopoulos D, Lu G, Hester L, Kass DA, Hasday J, Wang Y (2005) p38 MAP kinase mediates inflammatory cytokine induction in cardiomyocytes and extracellular matrix remodeling in heart. Circulation 111(19):2494-2502. https://doi.org/10.1161/ 01.cir.0000165117.71483.0c

84. Huang G, Shi LZ, Chi H (2009) Regulation of JNK and p38 MAPK in the immune system: signal integration, propagation and termination. Cytokine 48(3):161-169. https://doi.org/10. 1016/j.cyto.2009.08.002

85. Weichhart T, Hengstschlager M, Linke M (2015) Regulation of innate immune cell function by mTOR. Nat Rev Immunol 15(10): 599-614. https://doi.org/10.1038/nri3901

86. Weichhart T, Saemann MD (2008) The PI3K/Akt/mTOR pathway in innate immune cells: emerging therapeutic applications. Ann Rheum Dis 67(Suppl 3):iii70-iii74. https://doi.org/10.1136/ard. 2008.098459

87. Lucas K, Morris G, Anderson G, Maes M (2015) The toll-like receptor radical cycle pathway: a new drug target in immunerelated chronic fatigue. CNS Neurol Disord Drug Targets 14(7): 838-854

88. Cuenda A, Rousseau S (2007) p38 MAP-kinases pathway regulation, function and role in human diseases. Biochim Biophys Acta 1773(8):1358-1375. https://doi.org/10.1016/j.bbamcr.2007.03. 010

89. Bachstetter AD, Van Eldik LJ (2010) The p38 MAP kinase family as regulators of proinflammatory cytokine production in degenerative diseases of the CNS. Aging Dis 1(3):199-211

90. Dhanasekaran DN, Reddy EP (2008) JNK signaling in apoptosis. Oncogene 27(48):6245-6251. https://doi.org/10.1038/onc.2008. 301

91. Lawrence T (2009) The nuclear factor NF-kB pathway in inflammation. Cold Spring Harb Perspect Biol 1(6):a001651. https://doi. org/10.1101/cshperspect.a001651

92. Morris G, Maes M (2012) Increased nuclear factor-kappaB and loss of p53 are key mechanisms in myalgic encephalomyelitis/ chronic fatigue syndrome (ME/CFS). Med Hypotheses 79(5): 607-613. https://doi.org/10.1016/j.mehy.2012.07.034
93. Morgan MJ, Z-g L (2011) Crosstalk of reactive oxygen species and NF-kB signaling. Cell Res 21(1):103-115. https://doi.org/10. 1038/cr.2010.178

94. Hoesel B, Schmid JA (2013) The complexity of NF-kB signaling in inflammation and cancer. Mol Cancer 12:86-86. https://doi.org/ 10.1186/1476-4598-12-86

95. Beurel E, Michalek SM, Jope RS (2010) Innate and adaptive immune responses regulated by glycogen synthase kinase-3 (GSK3). Trends Immunol 31(1):24. https://doi.org/10.1016/j.it.2009.09. 007

96. Hofmann C, Dunger N, Scholmerich J, Falk W, Obermeier F (2010) Glycogen synthase kinase 3-beta: a master regulator of toll-like receptor-mediated chronic intestinal inflammation. Inflamm Bowel Dis 16(11):1850-1858. https://doi.org/10.1002/ ibd. 21294

97. Taylor A, Harker JA, Chanthong K, Stevenson PG, Zuniga EI, Rudd CE Glycogen synthase kinase 3 inactivation drives T-betmediated downregulation of Co-receptor PD-1 to enhance CD8 $<$ sup $>+</$ sup $>$ cytolytic $T$ cell responses. Immunity 44(2): 274-286. https://doi.org/10.1016/j.immuni.2016.01.018

98. Cortés-Vieyra R, Bravo-Patiño A, Valdez-Alarcón JJ, Juárez MC, Finlay BB, Baizabal-Aguirre VM (2012) Role of glycogen synthase kinase- 3 beta in the inflammatory response caused by bacterial pathogens. J Inflammation 9(1):23. https://doi.org/10.1186/ 1476-9255-9-23

99. Wang H, Brown J, Gu Z, Garcia CA, Liang R, Alard P, Beurel E, Jope RS et al (2011) Convergence of the mammalian target of rapamycin complex 1- and glycogen synthase kinase 3-betasignaling pathways regulates the innate inflammatory response. J Immunol 186(9):5217-5226. https://doi.org/10.4049/jimmunol. 1002513

100. Powell JD, Pollizzi KN, Heikamp EB, Horton MR (2012) Regulation of immune responses by mTOR. Annu Rev Immunol 30:39-68. https://doi.org/10.1146/annurev-immunol020711-075024

101. Zhang K, Kaufman RJ (2008) From endoplasmic-reticulum stress to the inflammatory response. Nature 454(7203):455-462. https:// doi.org/10.1038/nature07203

102. Fischer R, Maier O (2015) Interrelation of oxidative stress and inflammation in neurodegenerative disease: role of TNF. Oxidative Med Cell Longev 2015:18. https://doi.org/10.1155/ 2015/610813

103. Habib N, Goswami G, Mungre S (2010) Inflammatory cytokines induce oxidative stress and apoptosis in PC12 cells. FASEB J 24(1 Supplement):485.488

104. Morris G, Maes M (2014) Oxidative and nitrosative stress and immune-inflammatory pathways in patients with myalgic encephalomyelitis (ME)/chronic fatigue syndrome (CFS). Curr Neuropharmacol 12:168-185

105. Cao SS, Kaufman RJ (2014) Endoplasmic reticulum stress and oxidative stress in cell fate decision and human disease. Antioxid Redox Signal 21(3):396-413. https://doi.org/10.1089/ ars.2014.5851

106. Morgan M, Liu Z (2011) Crosstalk of reactive oxygen species and NF-kappaB signaling. Cell Res 21:103-115

107. Nakajima S, Kitamura M (2013) Bidirectional regulation of NFkappaB by reactive oxygen species: a role of unfolded protein response. Free Radic Biol Med 65:162-174. https://doi.org/10. 1016/j.freeradbiomed.2013.06.020

108. Liu T, Wu L, Wang D, Wang H, Chen J, Yang C, Bao J, Wu C (2016) Role of reactive oxygen species-mediated MAPK and NF$\mathrm{KB}$ activation in polygonatum cyrtonema lectin-induced apoptosis and autophagy in human lung adenocarcinoma A549 cells. J Biochem 160(6):315-324. https://doi.org/10.1093/jb/mvw040

109. Santos CX, Stolf BS, Takemoto PV, Amanso AM, Lopes LR, Souza EB, Goto H, Laurindo FR (2009) Protein disulfide 
isomerase (PDI) associates with NADPH oxidase and is required for phagocytosis of Leishmania chagasi promastigotes by macrophages. J Leukoc Biol 86(4):989-998. https://doi.org/10.1189/jlb. 0608354

110. Zeeshan HM, Lee GH, Kim HR, Chae HJ (2016) Endoplasmic reticulum stress and associated ROS. Int J Mol Sci 17(3):327. https://doi.org/10.3390/ijms17030327

111. Wang J, Pareja KA, Kaiser CA, Sevier CS (2014) Redox signaling via the molecular chaperone BiP protects cells against endoplasmic reticulum-derived oxidative stress. eLife 3:e03496. https://doi. org/10.7554/eLife.03496

112. Higa A, Chevet E (2012) Redox signaling loops in the unfolded protein response. Cell Signal 24(8):1548-1555. https://doi.org/10. 1016/j.cellsig.2012.03.011

113. Perri ER, Thomas CJ, Parakh S, Spencer DM, Atkin JD (2016) The unfolded protein response and the role of protein disulfide isomerase in neurodegeneration. Front Cell Dev Biol 3 (80). doi: https://doi.org/10.3389/fcell.2015.00080

114. Nakamura T, Tu S, Akhtar MW, Sunico CR, Okamoto S, Lipton SA (2013) Aberrant protein s-nitrosylation in neurodegenerative diseases. Neuron 78(4):596-614. https://doi.org/10.1016/j.neuron. 2013.05.005

115. Luo B, Lee AS (2013) The critical roles of endoplasmic reticulum chaperones and unfolded protein response in tumorigenesis and anti-cancer therapies. Oncogene 32 (7). doi:https://doi.org/10. 1038/onc.2012.130

116. Oslowski CM, Urano F (2011) Measuring ER stress and the unfolded protein response using mammalian tissue culture system. Methods Enzymol 490:71-92. https://doi.org/10.1016/B978-012-385114-7.00004-0

117. Janiszewski M, Lopes LR, Carmo AO, Pedro MA, Brandes RP, Santos CX, Laurindo FR (2005) Regulation of NAD(P)H oxidase by associated protein disulfide isomerase in vascular smooth muscle cells. J Biol Chem 280(49):40813-40819. https://doi.org/10. 1074/jbc.M509255200

118. Jaronen M, Goldsteins G, Koistinaho J (2014) ER stress and unfolded protein response in amyotrophic lateral sclerosis - a controversial role of protein disulphide isomerase. Front Cell Neurosci 8:402. https://doi.org/10.3389/fncel.2014.00402

119. Trevelin SC, Lopes LR (2015) Protein disulfide isomerase and Nox: new partners in redox signaling. Curr Pharm Des 21(41): 5951-5963

120. Li G, Mongillo M, Chin K-T, Harding H, Ron D, Marks AR, Tabas I (2009) Role of ERO1- $\alpha$-mediated stimulation of inositol 1,4,5-triphosphate receptor activity in endoplasmic reticulum stress-induced apoptosis. J Cell Biol 186(6):783-792. https://doi. org/10.1083/jcb.200904060

121. Katsuyama M, Matsuno K, Yabe-Nishimura C (2012) Physiological roles of NOX/NADPH oxidase, the superoxidegenerating enzyme. J Clin Biochem Nutr 50(1):9-22. https:// doi.org/10.3164/jcbn.11-06SR

122. Lassegue B, San Martin A, Griendling KK (2012) Biochemistry, physiology, and pathophysiology of NADPH oxidases in the cardiovascular system. Circ Res 110(10):1364-1390. https://doi.org/ 10.1161/circresaha.111.243972

123. Lassegue B, Griendling KK (2010) NADPH oxidases: functions and pathologies in the vasculature. Arterioscler Thromb Vasc Biol 30(4):653-661. https://doi.org/10.1161/atvbaha.108.181610

124. Balaban RS, Nemoto S, Finkel T (2005) Mitochondria, oxidants, and aging. Cell 120(4):483-495. https://doi.org/10.1016/j.cell. 2005.02.001

125. Fernandes DC, Manoel AH, Wosniak J Jr, Laurindo FR (2009) Protein disulfide isomerase overexpression in vascular smooth muscle cells induces spontaneous preemptive NADPH oxidase activation and Nox1 mRNA expression: effects of nitrosothiol exposure. Arch Biochem Biophys 484(2):197-204
126. Nakamura T, Lipton SA (2011) S-nitrosylation of critical protein thiols mediates protein misfolding and mitochondrial dysfunction in neurodegenerative diseases. Antioxid Redox Signal 14(8): 1479-1492. https://doi.org/10.1089/ars.2010.3570

127. Benham AM, van Lith M, Sitia R (1617) Braakman I (2013) Ero1PDI interactions, the response to redox flux and the implications for disulfide bond formation in the mammalian endoplasmic reticulum. Philos Trans R Soc Lond Ser B Biol Sci 368:20110403. https://doi.org/10.1098/rstb.2011.0403

128. Tavender TJ, Bulleid NJ (2010) Molecular mechanisms regulating oxidative activity of the Ero1 family in the endoplasmic reticulum. Antioxid Redox Signal 13(8):1177-1187. https://doi.org/10.1089/ ars.2010.3230

129. Zhang L, Niu Y, Zhu L, Fang J, Wang X, Wang L, Wang CC (2014) Different interaction modes for protein-disulfide isomerase (PDI) as an efficient regulator and a specific substrate of endoplasmic reticulum oxidoreductin-1alpha (Erolalpha). J Biol Chem 289(45):31188-31199. https://doi.org/10.1074/jbc.M114.602961

130. Kozlov G, Maattanen P, Thomas DY, Gehring K (2010) A structural overview of the PDI family of proteins. FEBS J 277(19): 3924-3936. https://doi.org/10.1111/j.1742-4658.2010.07793.x

131. Baker KM, Chakravarthi S, Langton KP, Sheppard AM, Lu H, Bulleid NJ (2008) Low reduction potential of Ero 1alpha regulatory disulphides ensures tight control of substrate oxidation. EMBO J 27(22):2988-2997. https://doi.org/10.1038/emboj.2008.230

132. Chambers JE, Tavender TJ, Oka OBV, Warwood S, Knight D, Bulleid NJ (2010) The reduction potential of the active site disulfides of human protein disulfide isomerase limits oxidation of the enzyme by Ero1 $\alpha$. J Biol Chem 285(38):29200-29207. https://doi.org/10.1074/jbc.M110.156596

133. Nguyen VD, Wallis K, Howard MJ, Haapalainen AM, Salo KE, Saaranen MJ, Sidhu A, Wierenga RK et al (2008) Alternative conformations of the $\mathrm{x}$ region of human protein disulphideisomerase modulate exposure of the substrate binding b' domain. J Mol Biol 383(5):1144-1155. https://doi.org/10.1016/j.jmb.2008. 08.085

134. Wang C, Chen S, Wang X, Wang L, Wallis AK, Freedman RB, Wang C-c (2010) Plasticity of human protein disulfide isomerase: evidence for mobility around the $\mathrm{x}$-linker region and its functional significance. J Biol Chem 285(35):26788-26797. https://doi.org/ 10.1074/jbc.M110.107839

135. Zito E (2015) ERO1: a protein disulfide oxidase and $\mathrm{H} 2 \mathrm{O} 2$ producer. Free Radic Biol Med 83:299-304. https://doi.org/10.1016/j. freeradbiomed.2015.01.011

136. Ramming T, Okumura M, Kanemura S, Baday S, Birk J, Moes S, Spiess M, Jeno P et al (2015) A PDI-catalyzed thiol-disulfide switch regulates the production of hydrogen peroxide by human Ero1. Free Radic Biol Med 83:361-372. https://doi.org/10.1016/j. freeradbiomed.2015.02.011

137. Hatahet F, Ruddock LW (2009) Protein disulfide isomerase: a critical evaluation of its function in disulfide bond formation. Antioxid Redox Signal 11(11):2807-2850. https://doi.org/10. 1089/ars.2009.2466

138. Wang L, Zhang L, Niu Y, Sitia R, Wang CC (2014) Glutathione peroxidase 7 utilizes hydrogen peroxide generated by Erolalpha to promote oxidative protein folding. Antioxid Redox Signal 20(4):545-556. https://doi.org/10.1089/ars.2013.5236

139. Halloran M, Parakh S, Atkin JD (2013) The role of S-nitrosylation and S-glutathionylation of protein disulphide isomerase in protein misfolding and neurodegeneration. Int J Cell Biol. https://doi.org/ $10.1155 / 2013 / 797914$

140. Forrester MT, Benhar M, Stamler JS (2006) Nitrosative stress in the ER: a new role for S-nitrosylation in neurodegenerative diseases. ACS Chem Biol 1(6):355-358. https://doi.org/10.1021/ cb600244c 
141. Uehara T, Nakamura T, Yao D, Shi ZQ, Gu Z, Ma Y, Masliah E, Nomura Y et al (2006) S-nitrosylated protein-disulphide isomerase links protein misfolding to neurodegeneration. Nature 441(7092): 513-517. https://doi.org/10.1038/nature04782

142. Andreu CI, Woehlbier U, Torres M, Hetz C (2012) Protein disulfide isomerases in neurodegeneration: from disease mechanisms to biomedical applications. FEBS Lett 586(18):2826-2834. https://doi.org/10.1016/j.febslet.2012.07.023

143. Walker AK, Farg MA, Bye CR, McLean CA, Horne MK, Atkin JD (2010) Protein disulphide isomerase protects against protein aggregation and is S-nitrosylated in amyotrophic lateral sclerosis. Brain 133(Pt 1):105-116. https://doi.org/10.1093/brain/awp267

144. Wu XF, Wang AF, Chen L, Huang EP, Xie WB, Liu C, Huang WY, Chen CX et al (2014) S-Nitrosylating protein disulphide isomerase mediates alpha-synuclein aggregation caused by methamphetamine exposure in PC12 cells. Toxicol Lett 230(1):19-27. https://doi.org/10.1016/j.toxlet.2014.07.026

145. Qi H, Li L, Shuai J (2015) Optimal microdomain crosstalk between endoplasmic reticulum and mitochondria for $\mathrm{Ca} 2+$ oscillations. Sci Rep 5:7984. https://doi.org/10.1038/srep07984 http:// www.nature.com/articles/srep07984\#supplementary-information

146. Arruda AP, Pers BM, Parlakgul G, Guney E, Inouye K, Hotamisligil GS (2014) Chronic enrichment of hepatic endoplasmic reticulum-mitochondria contact leads to mitochondrial dysfunction in obesity. Nat Med 20(12):1427-1435. https://doi.org/ 10.1038/nm.3735 http:/www.nature.com/nm/journal/v20/n12/ abs/nm.3735.html\#supplementary-information

147. Giorgi C, De Stefani D, Bononi A, Rizzuto R, Pinton P (2009) Structural and functional link between the mitochondrial network and the endoplasmic reticulum. Int J Biochem Cell Biol 41(10): 1817-1827. https://doi.org/10.1016/j.biocel.2009.04.010

148. Bravo-Sagua R, Rodriguez AE, Kuzmicic J, Gutierrez T, LopezCrisosto C, Quiroga C, Díaz-Elizondo J, Chiong M et al (2013) Cell death and survival through the endoplasmic reticulummitochondrial axis. Curr Mol Med 13(2):317-329

149. Szabadkai G, Bianchi K, Varnai P, De Stefani D, Wieckowski MR, Cavagna D, Nagy AI, Balla T et al (2006) Chaperone-mediated coupling of endoplasmic reticulum and mitochondrial $\mathrm{Ca} 2+$ channels. J Cell Biol 175(6):901-911. https://doi.org/10.1083/jcb. 200608073

150. Vance JE (1990) Phospholipid synthesis in a membrane fraction associated with mitochondria. J Biol Chem 265(13):7248-7256

151. Chen H, Detmer SA, Ewald AJ, Griffin EE, Fraser SE, Chan DC (2003) Mitofusins Mfn1 and Mfn2 coordinately regulate mitochondrial fusion and are essential for embryonic development. J Cell Biol 160(2):189-200. https://doi.org/10.1083/jcb.200211046

152. Koshiba T, Detmer SA, Kaiser JT, Chen H, McCaffery JM, Chan DC (2004) Structural basis of mitochondrial tethering by mitofusin complexes. Science 305(5685):858-862. https://doi. org/10.1126/science.1099793

153. Myhill N, Lynes EM, Nanji JA, Blagoveshchenskaya AD, Fei H, Carmine Simmen K, Cooper TJ, Thomas G et al (2008) The subcellular distribution of calnexin is mediated by PACS-2. Mol Biol Cell 19(7):2777-2788. https://doi.org/10.1091/mbc.e07-10-0995

154. Bui M, Gilady SY, Fitzsimmons RE, Benson MD, Lynes EM, Gesson K, Alto NM, Strack S et al (2010) Rab32 modulates apoptosis onset and mitochondria-associated membrane (MAM) properties. J Biol Chem 285(41):31590-31602. https://doi.org/ 10.1074/jbc.M110.101584

155. Friedman JR, Webster BM, Mastronarde DN, Verhey KJ, Voeltz GK (2010) ER sliding dynamics and ER-mitochondrial contacts occur on acetylated microtubules. J Cell Biol 190(3):363-375. https://doi.org/10.1083/jcb.200911024

156. Bravo R, Vicencio JM, Parra V, Troncoso R, Munoz JP, Bui M, Quiroga C, Rodriguez AE et al (2011) Increased ERmitochondrial coupling promotes mitochondrial respiration and bioenergetics during early phases of ER stress. J Cell Sci 124(13):2143-2152. https://doi.org/10.1242/jcs.080762

157. Margineantu DH, Gregory Cox W, Sundell L, Sherwood SW, Beechem JM, Capaldi RA (2002) Cell cycle dependent morphology changes and associated mitochondrial DNA redistribution in mitochondria of human cell lines. Mitochondrion 1(5):425-435

158. Venkatesh S, Lee J, Singh K, Lee I, Suzuki CK (2012) Multitasking in the mitochondrion by the ATP-dependent Lon protease. Biochim Biophys Acta 1823(1):56-66. https://doi.org/ 10.1016/j.bbamcr.2011.11.003

159. Adam-Vizi V, Starkov AA (2010) Calcium and mitochondrial reactive oxygen species generation: how to read the facts. J Alzheimer's Dis 20(Suppl 2):S413-S426. https://doi.org/10. 3233/JAD-2010-100465

160. Feissner RF, Skalska J, Gaum WE, Sheu SS (2009) Crosstalk signaling between mitochondrial $\mathrm{Ca} 2+$ and ROS. Front Biosci (Landmark edition) 14:1197-1218

161. Brookes PS, Yoon Y, Robotham JL, Anders MW, Sheu S-S (2004) Calcium, ATP, and ROS: a mitochondrial love-hate triangle. Am J Physiol Cell Physiol 287(4):C817-C833. https://doi.org/10.1152/ ajpcell.00139.2004

162. Traaseth N, Elfering S, Solien J, Haynes V, Giulivi C (2004) Role of calcium signaling in the activation of mitochondrial nitric oxide synthase and citric acid cycle. Biochim Biophys Acta 1658(1-2): 64-71. https://doi.org/10.1016/j.bbabio.2004.04.015

163. Giulivi C, Kato K, Cooper CE (2006) Nitric oxide regulation of mitochondrial oxygen consumption I: cellular physiology. Am J Physiol Cell Physiol 291(6):C1225-C1231. https://doi.org/10. 1152/ajpcell.00307.2006

164. Erusalimsky J, Moncada S (2007) Nitric oxide and mitochondrial signaling: from physiology to pathophysiology. Arterioscler Thromb Vasc Biol 27:2524-2531

165. Morris G, Walder K, Carvalho AF, Tye SJ, Lucas K, Berk M, Maes M (2017) The role of hypernitrosylation in the pathogenesis and pathophysiology of neuroprogressive diseases. Neurosci Biobehav Rev. https://doi.org/10.1016/j.neubiorev.2017.07.017

166. Doulias PT, Tenopoulou M, Greene JL, Raju K, Ischiropoulos H (2013) Nitric oxide regulates mitochondrial fatty acid metabolism through reversible protein S-nitrosylation. Sci Signal 6(256):rs1. https://doi.org/10.1126/scisignal.2003252

167. Mailloux RJ, Jin X, Willmore WG (2014) Redox regulation of mitochondrial function with emphasis on cysteine oxidation reactions(). Redox Biol 2:123-139. https://doi.org/10.1016/j.redox. 2013.12.011

168. Murray CI, Uhrigshardt H, O'Meally RN, Cole RN, Van Eyk JE (2012) Identification and quantification of S-nitrosylation by cysteine reactive tandem mass tag switch assay. Mol Cell Proteomics 11(2):M111.013441. https://doi.org/10.1074/mcp.M111.013441

169. Drose S, Brandt U, Wittig I (2014) Mitochondrial respiratory chain complexes as sources and targets of thiol-based redox-regulation. Biochim Biophys Acta 1844(8):1344-1354. https://doi. org/10.1016/j.bbapap.2014.02.006

170. Piantadosi CA (2012) Regulation of mitochondrial processes by protein S-nitrosylation. Biochim Biophys Acta 1820(6):712-721. https://doi.org/10.1016/j.bbagen.2011.03.008

171. Morris G, Berk M, Klein H, Walder K, Galecki P, Maes M (2016) Nitrosative stress, hypernitrosylation, and autoimmune responses to nitrosylated proteins: new pathways in neuroprogressive disorders including depression and chronic fatigue syndrome. Mol Neurobiol. https://doi.org/10.1007/s12035-016-9975-2

172. Sarti P, Arese M, Forte E, Giuffre A, Mastronicola D (2012) Mitochondria and nitric oxide: chemistry and pathophysiology. Adv Exp Med Biol 942:75-92. https://doi.org/10.1007/978-94007-2869-1_4

173. Zhang J, Jin B, Li L, Block E, Patel J (2005) Nitric oxide-induced persistent inhibition and nitrosylation of active site cysteine 
residues of mitochondrial cytochrome-c oxidase in lung endothelial cells. Am J Physiol Cell Physiol 288:C840-C849

174. Sarti P, Forte E, Giuffre A, Mastronicola D, Magnifico M, Arese M (2012) The chemical interplay between nitric oxide and mitochondrial cytochrome c oxidase: reactions, effectors and pathophysiology. Int J Cell Biol 2012:571067

175. Sarti P, Giuffre A, Barone M, Forte E, Mastronicola D, Brunori M (2003) Nitric oxide and cytochrome oxidase: reaction mechanisms from the enzyme to the cell. Free Radic Biol Med 34:509-520

176. Bolanos J, Almeida A, Moncada S (2010) Glycolysis: a bioenergetic or a survival pathway? Trends Biochem Sci 35:145-149

177. Shiva S, Sack MN, Greer JJ, Duranski M, Ringwood LA, Burwell L, Wang X, MacArthur PH et al (2007) Nitrite augments tolerance to ischemia/reperfusion injury via the modulation of mitochondrial electron transfer. J Exp Med 204(9):2089-2102. https://doi.org/ 10.1084/jem.20070198

178. Sun J, Morgan M, Shen RF, Steenbergen C, Murphy E (2007) Preconditioning results in S-nitrosylation of proteins involved in regulation of mitochondrial energetics and calcium transport. Circ Res 101(11):1155-1163. https://doi.org/10.1161/circresaha.107. 155879

179. Xu W, Liu L, Charles IG, Moncada S (2004) Nitric oxide induces coupling of mitochondrial signalling with the endoplasmic reticulum stress response. Nat Cell Biol 6(11):1129-1134. https://doi. org $/ 10.1038 /$ ncb 1188

180. Murphy Michael P (2009) How mitochondria produce reactive oxygen species. Biochem J 417(1):1-13. https://doi.org/10.1042/ bj20081386

181. Baumgartner HK, Gerasimenko JV, Thorne C, Ferdek P, Pozzan T, Tepikin AV, Petersen OH, Sutton R et al (2009) Calcium elevation in mitochondria is the main $\mathrm{Ca} 2+$ requirement for mitochondrial permeability transition pore (mPTP) opening. J Biol Chem 284(31):20796-20803. https://doi.org/10.1074/jbc.m109.025353

182. Gerasimenko JV, Gerasimenko OV, Palejwala A, Tepikin AV, Petersen OH, Watson AJ (2002) Menadione-induced apoptosis: roles of cytosolic $\mathrm{Ca}(2+)$ elevations and the mitochondrial permeability transition pore. J Cell Sci 115(Pt 3):485-497

183. Li G, Mongillo M, Chin KT, Harding H, Ron D, Marks AR, Tabas I (2009) Role of ERO1-alpha-mediated stimulation of inositol 1,4, 5 -triphosphate receptor activity in endoplasmic reticulum stressinduced apoptosis. J Cell Biol 186(6):783-792. https://doi.org/10. 1083/jcb.200904060

184. Jacobson J, Duchen MR (2002) Mitochondrial oxidative stress and cell death in astrocytes - requirement for stored $\mathrm{Ca} 2+$ and sustained opening of the permeability transition pore. J Cell Sci 115(Pt 6):1175-1188

185. Runkel ED, Liu S, Baumeister R, Schulze E (2013) Surveillanceactivated defenses block the ROS-induced mitochondrial unfolded protein response. PLoS Genet 9(3):e1003346. https://doi.org/10. 1371/journal.pgen.1003346

186. Yoneda T, Benedetti C, Urano F, Clark SG, Harding HP, Ron D (2004) Compartment-specific perturbation of protein handling activates genes encoding mitochondrial chaperones. J Cell Sci 117(Pt 18):4055-4066. https://doi.org/10.1242/jcs.01275

187. Nargund AM, Pellegrino MW, Fiorese CJ, Baker BM, Haynes CM (2012) Mitochondrial import efficiency of ATFS-1 regulates mitochondrial UPR activation. Science 337(6094):587-590. https://doi.org/10.1126/science.1223560

188. Liu Y, Samuel BS, Breen PC, Ruvkun G (2014) Caenorhabditis elegans pathways that surveil and defend mitochondria. Nature 508(7496):406-410. https://doi.org/10.1038/nature13204

189. Huang L-J, Ho J-J, Yang R-C (2013) Mitochondrial unfolded protein response (mtUPR) participates in hepatic dysfunction in sepsis. FASEB J 27(1 Supplement):872.875

190. Lin Y-F, Haynes Cole M (2016) Metabolism and the UPRmt. Mol Cell 61(5):677-682. https://doi.org/10.1016/j.molcel.2016.02.004
191. Pellegrino MW, Nargund AM, Haynes CM (2013) Signaling the mitochondrial unfolded protein response. Biochim Biophys Acta 1833(2):410-416. https://doi.org/10.1016/j.bbamcr.2012.02.019

192. Mottis A, Jovaisaite V, Auwerx J (2014) The mitochondrial unfolded protein response in mammalian physiology. Mamm Genome 25(9):424-433. https://doi.org/10.1007/s00335-0149525-Z

193. Papa L, Germain D (2014) SirT3 regulates the mitochondrial unfolded protein response. Mol Cell Biol 34(4):699-710. https://doi. org/10.1128/mcb.01337-13

194. Papa L, Germain D (2011) Estrogen receptor mediates a distinct mitochondrial unfolded protein response. J Cell Sci 124(Pt 9): 1396-1402. https://doi.org/10.1242/jcs.078220

195. Radke S, Chander H, Schäfer P, Meiss G, Krüger R, Schulz JB, Germain D (2008) Mitochondrial protein quality control by the proteasome involves ubiquitination and the protease Omi. J Biol Chem 283(19):12681-12685. https://doi.org/10.1074/jbc. C800036200

196. Arnould T, Michel S, Renard P (2015) Mitochondria retrograde signaling and the UPR mt: where are we in mammals? Int J Mol Sci 16(8):18224-18251. https://doi.org/10.3390/ijms 160818224

197. Baker MJ, Tatsuta T, Langer T (2011) Quality control of mitochondrial proteostasis. Cold Spring Harb Perspect Biol 3(7). https://doi.org/10.1101/cshperspect.a007559

198. Horibe T, Hoogenraad NJ (2007) The chop gene contains an element for the positive regulation of the mitochondrial unfolded protein response. PLoS One 2(9):e835. https://doi.org/10.1371/ journal.pone. 0000835

199. van der Laan M, Hutu DP, Rehling P (2010) On the mechanism of preprotein import by the mitochondrial presequence translocase. Biochim Biophys Acta 1803(6):732-739. https://doi.org/10.1016/ j.bbamcr.2010.01.013

200. Chacinska A, Koehler CM, Milenkovic D, Lithgow T, Pfanner N (2009) Importing mitochondrial proteins: machineries and mechanisms. Cell 138(4):628-644. https://doi.org/10.1016/j.cell.2009. 08.005

201. Harbauer AB, Zahedi RP, Sickmann A, Pfanner N, Meisinger C (2014) The protein import machinery of mitochondria - a regulatory hub in metabolism, stress, and disease. Cell Metab 19(3):357372. https://doi.org/10.1016/j.cmet.2014.01.010

202. Opalinska M, Meisinger C (2015) Metabolic control via the mitochondrial protein import machinery. Curr Opin Cell Biol 33:4248. https://doi.org/10.1016/j.ceb.2014.11.001

203. Pellegrino MW, Haynes CM (2015) Mitophagy and the mitochondrial unfolded protein response in neurodegeneration and bacterial infection. BMC Biol 13(1):22. https://doi.org/10.1186/s12915015-0129-1

204. Wrobel L, Topf U, Bragoszewski P, Wiese S, Sztolsztener ME, Oeljeklaus S, Varabyova A, Lirski M et al (2015) Mistargeted mitochondrial proteins activate a proteostatic response in the cytosol. Nature 524(7566):485-488. https://doi.org/10.1038/ nature 14951

205. Wang X, Chen XJ (2015) A cytosolic network suppressing mitochondria-mediated proteostatic stress and cell death. Nature 524(7566):481-484. https://doi.org/10.1038/nature14859

206. Fiorese CJ, Schulz AM, Lin YF, Rosin N, Pellegrino MW, Haynes CM (2016) The transcription factor ATF5 mediates a mammalian mitochondrial UPR. Curr Biol 26(15):2037-2043. https://doi.org/ 10.1016/j.cub.2016.06.002

207. Martinus RD, Garth GP, Webster TL, Cartwright P, Naylor DJ, Hoj PB, Hoogenraad NJ (1996) Selective induction of mitochondrial chaperones in response to loss of the mitochondrial genome. Eur J Biochem 240(1):98-103

208. Moullan N, Mouchiroud L, Wang X, Ryu D, Williams EG, Mottis A, Jovaisaite V, Frochaux MV et al (2015) Tetracyclines disturb mitochondrial function across eukaryotic models: a call for 
caution in biomedical research. Cell Rep. https://doi.org/10.1016/ j.celrep.2015.02.034

209. Mouchiroud L, Houtkooper RH, Moullan N, Katsyuba E, Ryu D, Canto C, Mottis A, Jo YS et al (2013) The NAD(+)/sirtuin pathway modulates longevity through activation of mitochondrial UPR and FOXO signaling. Cell 154(2):430-441. https://doi.org/ 10.1016/j.cell.2013.06.016

210. Tauffenberger A, Vaccaro A, Parker JA (2016) Fragile lifespan expansion by dietary mitohormesis in C. elegans. Aging (Albany NY) 8(1):50-61. https://doi.org/10.18632/aging.100863

211. Zhao Q, Wang J, Levichkin IV, Stasinopoulos S, Ryan MT, Hoogenraad NJ (2002) A mitochondrial specific stress response in mammalian cells. EMBO J 21(17):4411-4419

212. Nargund AM, Fiorese CJ, Pellegrino MW, Deng P, Haynes CM (2015) Mitochondrial and nuclear accumulation of the transcription factor ATFS-1 promotes OXPHOS recovery during the UPR(mt). Mol Cell 58(1):123-133. https://doi.org/10.1016/j. molcel.2015.02.008

213. Germain D (2016) Sirtuins and the estrogen receptor as regulators of the mammalian mitochondrial UPR in cancer and aging. Adv Cancer Res 130:211-256. https://doi.org/10.1016/bs.acr.2016.01. 004

214. Morris G, Walder K, McGee SL, Dean OM, Tye SJ, Maes M, Berk $M$ (2017) A model of the mitochondrial basis of bipolar disorder. Neurosci Biobehav Rev 74(Pt A):1-20. https://doi.org/10.1016/j. neubiorev.2017.01.014

215. Kauppinen A, Suuronen T, Ojala J, Kaarniranta K, Salminen A (2013) Antagonistic crosstalk between NF-kappaB and SIRT1 in the regulation of inflammation and metabolic disorders. Cell Signal 25(10):1939-1948. https://doi.org/10.1016/j.cellsig.2013. 06.007

216. Tang BL (2016) Sirt1 and the mitochondria. Mol Cells 39(2):8795. https://doi.org/10.14348/molcells.2016.2318

217. Kotiadis VN, Duchen MR, Osellame LD (2014) Mitochondrial quality control and communications with the nucleus are important in maintaining mitochondrial function and cell health. Biochim Biophys Acta 1840(4):1254-1265. https://doi.org/10. 1016/j.bbagen.2013.10.041

218. Quiros PM, Mottis A, Auwerx J (2016) Mitonuclear communication in homeostasis and stress. Nat Rev Mol Cell Biol 17(4):213226. https://doi.org/10.1038/nrm.2016.23

219. Palikaras K, Lionaki E, Tavernarakis N (2015) Coupling mitogenesis and mitophagy for longevity. Autophagy 11(8): 1428-1430. https://doi.org/10.1080/15548627.2015.1061172

220. Melser S, Lavie J, Benard G (2015) Mitochondrial degradation and energy metabolism. Biochim Biophys Acta 1853(10 Pt B): 2812-2821. https://doi.org/10.1016/j.bbamcr.2015.05.010

221. Jeyaraju DV, Cisbani G, Pellegrini L (2009) Calcium regulation of mitochondria motility and morphology. Biochim Biophys Acta 1787(11):1363-1373. https://doi.org/10.1016/j.bbabio.2008.12. 005

222. Distelmaier F, Valsecchi F, Forkink M, van Emst-de Vries S, Swarts HG, Rodenburg RJ, Verwiel ET, Smeitink JA et al (2012) Trolox-sensitive reactive oxygen species regulate mitochondrial morphology, oxidative phosphorylation and cytosolic calcium handling in healthy cells. Antioxid Redox Signal 17(12):1657-1669. https://doi.org/10.1089/ars.2011.4294

223. Senft D, Ronai ZA (2015) UPR, autophagy, and mitochondria crosstalk underlies the ER stress response. Trends Biochem Sci 40(3):141-148. https://doi.org/10.1016/j.tibs.2015.01.002

224. Andres AM, Stotland A, Queliconi BB, Gottlieb RA (2015) A time to reap, a time to sow: mitophagy and biogenesis in cardiac pathophysiology. J Mol Cell Cardiol 78:62-72. https://doi.org/10. 1016/j.yjmcc.2014.10.003

225. Palikaras K, Tavernarakis N (2014) Mitochondrial homeostasis: the interplay between mitophagy and mitochondrial biogenesis.
Exp Gerontol 56:182-188. https://doi.org/10.1016/j.exger.2014. 01.021

226. Westermann B (2012) Bioenergetic role of mitochondrial fusion and fission. Biochim Biophys Acta 1817(10):1833-1838. https:// doi.org/10.1016/j.bbabio.2012.02.033

227. Galloway CA, Lee H, Yoon Y (2012) Mitochondrial morphologyemerging role in bioenergetics. Free Radic Biol Med 53(12): 2218-2228. https://doi.org/10.1016/j.freeradbiomed.2012.09.035

228. Schrepfer E, Scorrano L (2016) Mitofusins, from mitochondria to metabolism. Mol Cell 61(5):683-694. https://doi.org/10.1016/j. molcel.2016.02.022

229. Liesa M, Shirihai OS (2013) Mitochondrial dynamics in the regulation of nutrient utilization and energy expenditure. Cell Metab 17(4):491-506. https://doi.org/10.1016/j.cmet.2013.03.002

230. Narendra DP, Jin SM, Tanaka A, Suen D-F, Gautier CA, Shen J, Cookson MR, Youle RJ (2010) PINK1 is selectively stabilized on impaired mitochondria to activate Parkin. PLoS Biol 8(1): e1000298. https://doi.org/10.1371/journal.pbio.1000298

231. Greene AW, Grenier K, Aguileta MA, Muise S, Farazifard R, Haque ME, McBride HM, Park DS et al (2012) Mitochondrial processing peptidase regulates PINK1 processing, import and parkin recruitment. EMBO Rep 13(4):378-385. https://doi.org/ 10.1038/embor.2012.14

232. Lazarou M, Jin Seok M, Kane Lesley A, Youle Richard J (2012) Role of PINK1 binding to the TOM complex and alternate intracellular membranes in recruitment and activation of the E3 ligase Parkin. Dev Cell 22(2):320-333. https://doi.org/10.1016/j.devcel. 2011.12.014

233. Okatsu K, Oka T, Iguchi M, Imamura K, Kosako H, Tani N, Kimura M, Go E et al (2012) PINK1 autophosphorylation upon membrane potential dissipation is essential for parkin recruitment to damaged mitochondria. Nat Commun 3:1016. https://doi.org/ $10.1038 /$ ncomms 2016

234. Kazlauskaite A, Kondapalli C, Gourlay R, Campbell DG, Ritorto MS, Hofmann K, Alessi DR, Knebel A et al (2014) Parkin is activated by PINK1-dependent phosphorylation of ubiquitin at Ser65. Biochem J 460(1):127-139. https://doi.org/10.1042/ bj20140334

235. Koyano F, Matsuda N (2015) Molecular mechanisms underlying PINK1 and parkin catalyzed ubiquitylation of substrates on damaged mitochondria. Biochim Biophys Acta 1853(10 Pt B):27912796. https://doi.org/10.1016/j.bbamcr.2015.02.009

236. Ordureau A, Heo JM, Duda DM, Paulo JA, Olszewski JL, Yanishevski D, Rinehart J, Schulman BA et al (2015) Defining roles of PARKIN and ubiquitin phosphorylation by PINK1 in mitochondrial quality control using a ubiquitin replacement strategy. Proc Natl Acad Sci U S A 112(21):6637-6642. https://doi. org/10.1073/pnas.1506593112

237. Durcan TM, Fon EA (2015) The three 'P's of mitophagy: PARKIN, PINK1, and post-translational modifications. Genes Dev 29(10):989-999. https://doi.org/10.1101/gad.262758.115

238. Chan NC, Salazar AM, Pham AH, Sweredoski MJ, Kolawa NJ, Graham RLJ, Hess S, Chan DC (2011) Broad activation of the ubiquitin-proteasome system by parkin is critical for mitophagy. Hum Mol Genet 20(9):1726-1737. https://doi.org/10.1093/hmg/ ddr048

239. Tanaka A, Cleland MM, Xu S, Narendra DP, Suen DF, Karbowski M, Youle RJ (2010) Proteasome and p97 mediate mitophagy and degradation of mitofusins induced by Parkin. J Cell Biol 191(7): 1367-1380. https://doi.org/10.1083/jcb.201007013

240. Poole AC, Thomas RE, Yu S, Vincow ES, Pallanck L (2010) The mitochondrial fusion-promoting factor mitofusin is a substrate of the PINK1/parkin pathway. PLoS One 5(4):e10054. https://doi. org/10.1371/journal.pone.0010054 
241. Ni H-M, Williams JA, Ding W-X (2015) Mitochondrial dynamics and mitochondrial quality control. Redox Biol 4:6-13. https://doi. org/10.1016/j.redox.2014.11.006

242. Bernhardt D, Muller M, Reichert AS, Osiewacz HD (2015) Simultaneous impairment of mitochondrial fission and fusion reduces mitophagy and shortens replicative lifespan. Sci Rep 5: 7885. https://doi.org/10.1038/srep07885

243. Ashrafi G, Schwarz TL (2013) The pathways of mitophagy for quality control and clearance of mitochondria. Cell Death Differ 20(1):31-42. https://doi.org/10.1038/cdd.2012.81

244. Shirihai OS, Song M, Dorn GW 2nd (2015) How mitochondrial dynamism orchestrates mitophagy. Circ Res 116(11):1835-1849. https://doi.org/10.1161/circresaha.116.306374

245. Figge MT, Reichert AS, Meyer-Hermann M, Osiewacz HD (2012) Deceleration of fusion-fission cycles improves mitochondrial quality control during aging. PLoS Comput Biol 8(6): e1002576. https://doi.org/10.1371/journal.pcbi.1002576

246. Sin J, Andres AM, Taylor DJ, Weston T, Hiraumi Y, Stotland A, Kim BJ, Huang C et al (2016) Mitophagy is required for mitochondrial biogenesis and myogenic differentiation of $\mathrm{C} 2 \mathrm{C} 12$ myoblasts. Autophagy 12(2):369-380. https://doi.org/10.1080/ 15548627.2015.1115172

247. Scarpulla RC (2011) Metabolic control of mitochondrial biogenesis through the PGC-1 family regulatory network. Biochim Biophys Acta 1813(7):1269-1278. https://doi.org/10.1016/j. bbamcr.2010.09.019

248. Suliman HB, Sweeney TE, Withers CM, Piantadosi CA (2010) Co-regulation of nuclear respiratory factor- 1 by NFkappaB and CREB links LPS-induced inflammation to mitochondrial biogenesis. J Cell Sci 123(Pt 15):2565-2575. https://doi.org/10.1242/jcs. 064089

249. Cherry AD, Piantadosi CA (2015) Regulation of mitochondrial biogenesis and its intersection with inflammatory responses. Antioxid Redox Signal 22(12):965-976. https://doi.org/10.1089/ ars.2014.6200

250. Peng K, Yang L, Wang J, Ye F, Dan G, Zhao Y, Cai Y, Cui Z, Ao L, Liu J, Zou Z, Sai Y, Cao J (2016) The Interaction of mitochondrial biogenesis and fission/fusion mediated by PGC- $1 \alpha$ regulates rotenone-induced dopaminergic neurotoxicity. Mol Neurobiol:115. doi:https://doi.org/10.1007/s12035-016-9944-9

251. Chan DC (2006) Mitochondrial fusion and fission in mammals. Annu Rev Cell Dev Biol 22(1):79-99. https://doi.org/10.1146/ annurev.cellbio.22.010305.104638

252. Ferguson SM, De Camilli P (2012) Dynamin, a membraneremodelling GTPase. Nat Rev Mol Cell Biol 13(2):75-88 http:// www.nature.com/nrm/journal/v13/n2/suppinfo/nrm3266_S1. $\mathrm{html}$

253. Chen H (2005) Disruption of fusion results in mitochondrial heterogeneity and dysfunction. J Biol Chem 280(28):26185-26192. https://doi.org/10.1074/jbc.m503062200

254. Cipolat S, de Brito OM, Dal Zilio B, Scorrano L (2004) OPA1 requires mitofusin 1 to promote mitochondrial fusion. Proc Natl Acad Sci 101(45):15927-15932. https://doi.org/10.1073/pnas. 0407043101

255. van der Bliek AM, Shen Q, Kawajiri S (2013) Mechanisms of mitochondrial fission and fusion. Cold Spring Harb Perspect Biol 5(6)

256. Wei Y, Chiang WC, Sumpter R Jr, Mishra P, Levine B (2017) Prohibitin 2 is an inner mitochondrial membrane mitophagy receptor. Cell 168(1-2):224-238.e210. https://doi.org/10.1016/j. cell.2016.11.042

257. Zorzano A, Hernandez-Alvarez MI, Sebastian D, Munoz JP (2015) Mitofusin 2 as a driver that controls energy metabolism and insulin signaling. Antioxid Redox Signal 22(12):1020-1031. https://doi.org/10.1089/ars.2014.6208
258. Sebastian D, Hernandez-Alvarez MI, Segales J, Sorianello E, Munoz JP, Sala D, Waget A, Liesa M et al (2012) Mitofusin 2 (Mfn2) links mitochondrial and endoplasmic reticulum function with insulin signaling and is essential for normal glucose homeostasis. Proc Natl Acad Sci U S A 109(14):5523-5528. https://doi. org/10.1073/pnas.1108220109

259. Dorn GW 2nd, Song M, Walsh K (2015) Functional implications of mitofusin 2-mediated mitochondrial-SR tethering. J Mol Cell Cardiol 78:123-128. https://doi.org/10.1016/j.yjmcc.2014.09.015

260. Ainbinder A, Boncompagni S, Protasi F, Dirksen RT (2015) Role of mitofusin-2 in mitochondrial localization and calcium uptake in skeletal muscle. Cell Calcium 57(1):14-24. https://doi.org/10. 1016/j.ceca.2014.11.002

261. Lu ZQ, Tang LM, Zhao GJ, Yao YM, Zhu XM, Dong N, Yu Y (2013) Overactivation of mitogen-activated protein kinase and suppression of mitofusin-2 expression are two independent events in high mobility group box 1 protein-mediated $\mathrm{T}$ cell immune dysfunction. J Interf Cytokine Res 33(9):529-541. https://doi. org/10.1089/jir.2012.0054

262. Song Z, Chen H, Fiket M, Alexander C, Chan DC (2007) OPA1 processing controls mitochondrial fusion and is regulated by mRNA splicing, membrane potential, and Yme1L. J Cell Biol 178(5):749-755. https://doi.org/10.1083/jcb.200704110

263. Olichon A, Landes T, Arnaune-Pelloquin L, Emorine LJ, Mils V, Guichet A, Delettre C, Hamel C et al (2007) Effects of OPA1 mutations on mitochondrial morphology and apoptosis: relevance to ADOA pathogenesis. J Cell Physiol 211(2):423-430. https:// doi.org/10.1002/jcp.20950

264. Amati-Bonneau P, Milea D, Bonneau D, Chevrollier A, Ferre M, Guillet V, Gueguen N, Loiseau D et al (2009) OPA1-associated disorders: phenotypes and pathophysiology. Int J Biochem Cell Biol 41(10):1855-1865. https://doi.org/10.1016/j.biocel.2009.04. 012

265. Kao SH, Yen MY, Wang AG, Yeh YL, Lin AL (2015) Changes in mitochondrial morphology and bioenergetics in human lymphoblastoid cells with four novel OPA1 mutations. Invest Ophthalmol Vis Sci 56(4):2269-2278. https://doi.org/10.1167/ iovs. 14-16288

266. Varanita T, Soriano ME, Romanello V, Zaglia T, Quintana-Cabrera R, Semenzato M, Menabo R, Costa V et al (2015) The OPA1dependent mitochondrial cristae remodeling pathway controls atrophic, apoptotic, and ischemic tissue damage. Cell Metab 21(6):834-844. https://doi.org/10.1016/j.cmet.2015.05.007

267. Patten DA, Wong J, Khacho M, Soubannier V, Mailloux RJ, Pilon-Larose K, MacLaurin JG, Park DS et al (2014) OPA1dependent cristae modulation is essential for cellular adaptation to metabolic demand. EMBO J 33(22):2676-2691. https://doi. org/10.15252/embj.201488349

268. Olichon A, Baricault L, Gas N, Guillou E, Valette A, Belenguer P, Lenaers G (2003) Loss of OPA1 perturbates the mitochondrial inner membrane structure and integrity, leading to cytochrome $\mathrm{c}$ release and apoptosis. J Biol Chem 278(10):7743-7746. https:// doi.org/10.1074/jbc.C200677200

269. Cogliati S, Frezza C, Soriano Maria E, Varanita T, QuintanaCabrera R, Corrado M, Cipolat S, Costa V et al (2013) Mitochondrial cristae shape determines respiratory chain supercomplexes assembly and respiratory efficiency. Cell 155(1):160-171. https://doi.org/10.1016/j.cell.2013.08.032

270. Sanjuan Szklarz LK, Scorrano L (2012) The antiapoptotic OPA1/ Parl couple participates in mitochondrial adaptation to heat shock. Biochim Biophys Acta 1817(10):1886-1893. https://doi.org/10. 1016/j.bbabio.2012.05.001

271. Sanderson TH, Raghunayakula S, Kumar R (2015) Release of mitochondrial Opa1 following oxidative stress in HT22 cells. Mol Cell Neurosci 64:116-122. https://doi.org/10.1016/j.mcn. 2014.12.007 
272. Laforge M, Rodrigues V, Silvestre R, Gautier C, Weil R, Corti O, Estaquier J (2016) NF-kappaB pathway controls mitochondrial dynamics. Cell Death Differ 23(1):89-98. https://doi.org/10. 1038/cdd.2015.42

273. Parra V, Verdejo HE, Iglewski M, Del Campo A, Troncoso R, Jones D, Zhu Y, Kuzmicic J et al (2014) Insulin stimulates mitochondrial fusion and function in cardiomyocytes via the AktmTOR-NFkappaB-Opa-1 signaling pathway. Diabetes 63(1):7588. https://doi.org/10.2337/db13-0340

274. Dabrowska A, Venero JL, Iwasawa R, M-k H, Rahman S, Boobis A, Hajji N (2015) PGC-1 $\alpha$ controls mitochondrial biogenesis and dynamics in lead-induced neurotoxicity. Aging (Albany NY) 7(9): 629-643

275. Wu M, Katta A, Gadde MK, Liu H, Kakarla SK, Fannin J, Paturi S, Arvapalli RK et al (2009) Aging-associated dysfunction of Akt/ protein kinase B: S-nitrosylation and acetaminophen intervention. PLoS One 4(7):e6430. https://doi.org/10.1371/journal.pone. 0006430

276. Yasukawa T, Tokunaga E, Ota H, Sugita H, Martyn JA, Kaneki M (2005) S-nitrosylation-dependent inactivation of Akt/protein kinase B in insulin resistance. J Biol Chem 280(9):7511-7518. https://doi.org/10.1074/jbc.M411871200

277. Marshall HE, Stamler JS (2001) Inhibition of NF-kappa B by Snitrosylation. Biochemistry 40(6):1688-1693

278. Kelleher ZT, Matsumoto A, Stamler JS, Marshall HE (2007) NOS2 regulation of NF-kappaB by S-nitrosylation of $\mathrm{p} 65$. J Biol Chem 282(42):30667-30672. https://doi.org/10.1074/jbc. M705929200

279. Westermann B (2010) Mitochondrial fusion and fission in cell life and death. Nat Rev Mol Cell Biol 11(12):872-884. https://doi.org/ 10.1038/nrm3013

280. Zhao GJ, Lu ZQ, Yao YM (2010) Advances in mitochondrial fusion-fission and $\mathrm{Ca} 2+$ signaling in mammals. Sheng li ke xue jin zhan [Progress in Physiology] 41(3):171-176

281. Kaddour-Djebbar I, Choudhary V, Brooks C, Ghazaly T, Lakshmikanthan V, Dong Z, Kumar MV (2010) Specific mitochondrial calcium overload induces mitochondrial fission in prostate cancer cells. Int J Oncol 36(6):1437-1444

282. Otera H, Ishihara N, Mihara K (2013) New insights into the function and regulation of mitochondrial fission. Biochim Biophys Acta 1833(5):1256-1268. https://doi.org/10.1016/j.bbamcr.2013. 02.002

283. Li J, Wang Y, Wang Y, Wen X, Ma XN, Chen W, Huang F, Kou J et al (2015) Pharmacological activation of AMPK prevents Drp1mediated mitochondrial fission and alleviates endoplasmic reticulum stress-associated endothelial dysfunction. J Mol Cell Cardiol 86:62-74. https://doi.org/10.1016/j.yjmcc.2015.07.010

284. Wikstrom JD, Israeli T, Bachar-Wikstrom E, Swisa A, Ariav Y, Waiss M, Kaganovich D, Dor Y et al (2013) AMPK regulates ER morphology and function in stressed pancreatic beta-cells via phosphorylation of DRP1. Mol Endocrinol 27(10):1706-1723. https://doi.org/10.1210/me.2013-1109

285. Mopert K, Hajek P, Frank S, Chen C, Kaufmann J, Santel A (2009) Loss of Drp1 function alters OPA1 processing and changes mitochondrial membrane organization. Exp Cell Res 315(13): 2165-2180. https://doi.org/10.1016/j.yexcr.2009.04.016

286. Nakamura T, Cieplak P, Cho DH, Godzik A, Lipton SA (2010) SNitrosylation of Drp1 links excessive mitochondrial fission to neuronal injury in neurodegeneration. Mitochondrion 10(5):573578. https://doi.org/10.1016/j.mito.2010.04.007

287. Barsoum MJ, Yuan H, Gerencser AA, Liot G, Kushnareva Y, Graber S, Kovacs I, Lee WD et al (2006) Nitric oxide-induced mitochondrial fission is regulated by dynamin-related GTPases in neurons. EMBO J 25(16):3900-3911. https://doi.org/10.1038/sj. emboj.7601253
288. Bossy-Wetzel E, Barsoum MJ, Godzik A, Schwarzenbacher R, Lipton SA (2003) Mitochondrial fission in apoptosis, neurodegeneration and aging. Curr Opin Cell Biol 15(6):706-716

289. Knott AB, Perkins G, Schwarzenbacher R, Bossy-Wetzel E (2008) Mitochondrial fragmentation in neurodegeneration. Nat Rev Neurosci 9(7):505-518. https://doi.org/10.1038/nrn2417

290. Bossy B, Petrilli A, Klinglmayr E, Chen J, Lutz-Meindl U, Knott AB, Masliah E, Schwarzenbacher R et al (2010) S-Nitrosylation of DRP1 does not affect enzymatic activity and is not specific to Alzheimer's disease. J Alzheimers Dis 20(Suppl 2):S513-S526. https://doi.org/10.3233/jad-2010-100552

291. Kageyama Y, Hoshijima M, Seo K, Bedja D, Sysa-Shah P, Andrabi SA, Chen W, Höke A et al (2014) Parkin-independent mitophagy requires Drp1 and maintains the integrity of mammalian heart and brain. EMBO J 33(23):2798-2813. https://doi.org/ 10.15252/embj.201488658

292. Kang J-W, Hong J-M, Lee S-M (2016) Melatonin enhances mitophagy and mitochondrial biogenesis in rats with carbon tetrachloride-induced liver fibrosis. J Pineal Res 60(4):383-393. https://doi.org/10.1111/jpi.12319

293. Lin C, Chao H, Li Z, Xu X, Liu Y, Hou L, Liu N, Ji J (2016) Melatonin attenuates traumatic brain injury-induced inflammation: a possible role for mitophagy. J Pineal Res 61(2):177-186. https://doi.org/10.1111/jpi.12337

294. Coto-Montes A, Boga JA, Rosales-Corral S, Fuentes-Broto L, Tan D-X, Reiter RJ (2012) Role of melatonin in the regulation of autophagy and mitophagy: a review. Mol Cell Endocrinol 361(1-2):12-23. https://doi.org/10.1016/j.mce.2012.04.009

295. Parameyong A, Govitrapong P, Chetsawang B (2015) Melatonin attenuates the mitochondrial translocation of mitochondrial fission proteins and Bax, cytosolic calcium overload and cell death in methamphetamine-induced toxicity in neuroblastoma SH-SY5Y cells. Mitochondrion 24:1-8. https://doi.org/10.1016/j.mito.2015. 07.004

296. Parameyong A, Charngkaew K, Govitrapong P, Chetsawang B (2013) Melatonin attenuates methamphetamine-induced disturbances in mitochondrial dynamics and degeneration in neuroblastoma SH-SY5Y cells. J Pineal Res 55(3):313-323. https://doi.org/ 10.1111/jpi.12078

297. Suwanjang W, Abramov AY, Charngkaew K, Govitrapong P, Chetsawang B (2016) Melatonin prevents cytosolic calcium overload, mitochondrial damage and cell death due to toxically high doses of dexamethasone-induced oxidative stress in human neuroblastoma SH-SY5Y cells. Neurochem Int 97:34-41. https://doi. org/10.1016/j.neuint.2016.05.003

298. Xu S, Pi H, Zhang L, Zhang N, Li Y, Zhang H, Tang J, Li H et al (2016) Melatonin prevents abnormal mitochondrial dynamics resulting from the neurotoxicity of cadmium by blocking calcium-dependent translocation of Drp1 to the mitochondria. J Pineal Res 60(3):291-302. https://doi.org/10.1111/jpi.12310

299. Hevia D, Gonzalez-Menendez P, Quiros-Gonzalez I, Miar A, Rodriguez-Garcia A, Tan DX, Reiter RJ, Mayo JC et al (2015) Melatonin uptake through glucose transporters: a new target for melatonin inhibition of cancer. J Pineal Res 58(2):234-250. https://doi.org/10.1111/jpi.12210

300. Tan D-X, Manchester LC, Qin L, Reiter RJ (2016) Melatonin: a mitochondrial targeting molecule involving mitochondrial protection and dynamics. Int J Mol Sci 17(12):2124. https://doi.org/10. 3390/ijms 17122124

301. Hsiao C-W, Peng T-I, Peng AC, Reiter RJ, Tanaka M, Lai Y-K, Jou M-J (2013) Long-term A $\beta$ exposure augments mCa2+-independent mROS-mediated depletion of cardiolipin for the shift of a lethal transient mitochondrial permeability transition to its permanent mode in NARP cybrids: a protective targeting of melatonin. $\mathrm{J}$ Pineal Res 54(1):107-125. https://doi.org/10.1111/jpi.12004 
302. Chuang J-I, Pan IL, Hsieh C-Y, Huang C-Y, Chen P-C, Shin JW (2016) Melatonin prevents the dynamin-related protein 1dependent mitochondrial fission and oxidative insult in the cortical neurons after 1-methyl-4-phenylpyridinium treatment. J Pineal Res 61(2):230-240. https://doi.org/10.1111/jpi.12343

303. Pei H, Du J, Song X, He L, Zhang Y, Li X, Qiu C, Zhang Y et al (2016) Melatonin prevents adverse myocardial infarction remodeling via Notch1/Mfn2 pathway. Free Radic Biol Med 97:408417. https://doi.org/10.1016/j.freeradbiomed.2016.06.015

304. Ganie SA, Dar TA, Bhat AH, Dar KB, Anees S, Zargar MA, Masood A (2016) Melatonin: a potential anti-oxidant therapeutic agent for mitochondrial dysfunctions and related disorders. Rejuvenation Res 19(1):21-40. https://doi.org/10.1089/rej.2015. 1704

305. Acuna Castroviejo D, Lopez LC, Escames G, Lopez A, Garcia JA, Reiter RJ (2011) Melatonin-mitochondria interplay in health and disease. Curr Top Med Chem 11(2):221-240. https://doi.org/10. 2174/156802611794863517

306. Agil A, El-Hammadi M, Jimenez-Aranda A, Tassi M, Abdo W, Fernandez-Vazquez G, Reiter RJ (2015) Melatonin reduces hepatic mitochondrial dysfunction in diabetic obese rats. J Pineal Res 59(1):70-79. https://doi.org/10.1111/jpi.12241

307. Jimenéz-Aranda A, Fernández-Vázquez G, Mohammad ASerrano M, Reiter RJ, Agil A (2014) Melatonin improves mitochondrial function in inguinal white adipose tissue of Zücker diabetic fatty rats. J Pineal Res 57(1):103-109. https://doi.org/10. 1111/jpi. 12147

308. Escames G, Lopez LC, Tapias V, Utrilla P, Reiter RJ, Hitos AB, Leon J, Rodriguez MI et al (2006) Melatonin counteracts inducible mitochondrial nitric oxide synthase-dependent mitochondrial dysfunction in skeletal muscle of septic mice. J Pineal Res 40(1): 71-78. https://doi.org/10.1111/j.1600-079X.2005.00281.x

309. Escames G (2003) Melatonin counteracts lipopolysaccharideinduced expression and activity of mitochondrial nitric oxide synthase in rats. FASEB J. https://doi.org/10.1096/fj.02-0692fje

310. Yeung HM, Hung MW, Fung ML (2008) Melatonin ameliorates calcium homeostasis in myocardial and ischemia-reperfusion injury in chronically hypoxic rats. J Pineal Res 45(4):373-382. https://doi.org/10.1111/j.1600-079X.2008.00601.x

311. Hakanson DO, Bergstrom WH (1990) Pineal and adrenal effects on calcium homeostasis in the rat. Pediatr Res 27(6):571-573. https://doi.org/10.1203/00006450-199006000-00006

312. Waseem M, Tabassum H, Parvez S (2016) Melatonin modulates permeability transition pore and 5-hydroxydecanoate induced KATP channel inhibition in isolated brain mitochondria. Mitochondrion 31:1-8. https://doi.org/10.1016/j.mito.2016.08. 005

313. Jumnongprakhon P, Govitrapong P, Tocharus C, Tungkum W, Tocharus J (2013) Protective effect of melatonin on methamphetamine-induced apoptosis in glioma cell line. Neurotox Res 25(3):286-294. https://doi.org/10.1007/s12640013-9419-y

314. Doerrier C, García JA, Volt H, Díaz-Casado ME, Lima-Cabello E, Ortiz F, Luna-Sánchez M, Escames G et al (2015) Identification of mitochondrial deficits and melatonin targets in liver of septic mice by high-resolution respirometry. Life Sci 121:158-165. https:// doi.org/10.1016/j.lfs.2014.11.031

315. Ortiz F, García JA, Acuña-Castroviejo D, Doerrier C, López A, Venegas C, Volt H, Luna-Sánchez M et al (2013) The beneficial effects of melatonin against heart mitochondrial impairment during sepsis: inhibition of iNOS and preservation of nNOS. J Pineal Res 56(1):71-81. https://doi.org/10.1111/jpi.12099

316. Yang Y, Duan W, Jin Z, Yi W, Yan J, Zhang S, Wang N, Liang Z et al (2013) JAK2/STAT3 activation by melatonin attenuates the mitochondrial oxidative damage induced by myocardial ischemia/ reperfusion injury. J Pineal Res 55(3):275-286. https://doi.org/10. 1111/jpi.12070

317. Huang W-Y, Jou M-J, Tsung IP (2013) mtDNA T8993G mutationinduced F1F0-ATP synthase defect augments mitochondrial dysfunction associated with hypoxia/reoxygenation: the protective role of melatonin. PLoS One 1(11):e81546. https://doi.org/10. 1371/journal.pone.0081546

318. Dragicevic N, Copes N, O’Neal-Moffitt G, Jin J, Buzzeo R, Mamcarz M, Tan J, Cao C et al (2011) Melatonin treatment restores mitochondrial function in Alzheimer's mice: a mitochondrial protective role of melatonin membrane receptor signaling. $\mathrm{J}$ Pineal Res 51(1):75-86. https://doi.org/10.1111/j.1600-079x. 2011.00864.x

319. Ionov M, Burchell V, Klajnert B, Bryszewska M, Abramov AY (2011) Mechanism of neuroprotection of melatonin against betaamyloid neurotoxicity. Neuroscience 180:229-237. https://doi. org/10.1016/j.neuroscience.2011.02.045

320. Raza H, John A, Brown EM, Benedict S, Kambal A (2008) Alterations in mitochondrial respiratory functions, redox metabolism and apoptosis by oxidant 4-hydroxynonenal and antioxidants curcumin and melatonin in PC12 cells. Toxicol Appl Pharmacol 226(2):161-168. https://doi.org/10.1016/j.taap.2007.09.002

321. Garcia JA, Volt H, Venegas C, Doerrier C, Escames G, Lopez LC, Acuna-Castroviejo D (2015) Disruption of the NF-kappaB/ NLRP3 connection by melatonin requires retinoid-related orphan receptor-alpha and blocks the septic response in mice. FASEB J 29(9):3863-3875. https://doi.org/10.1096/fj.15-273656

322. Tripathi DN, Jena GB (2010) Effect of melatonin on the expression of Nrf2 and NF-kappaB during cyclophosphamide-induced urinary bladder injury in rat. J Pineal Res 48(4):324-331. https:// doi.org/10.1111/j.1600-079X.2010.00756.X

323. Farez Mauricio F, Mascanfroni Ivan D, Méndez-Huergo Santiago P, Yeste A, Murugaiyan G, Garo Lucien P, Balbuena Aguirre María E, Patel B et al Melatonin contributes to the seasonality of multiple sclerosis relapses. Cell 162(6):1338-1352. https://doi. org/10.1016/j.cell.2015.08.025

324. Cardinali DP, Pagano ES, Scacchi Bernasconi PA, Reynoso R, Scacchi P (2013) Melatonin and mitochondrial dysfunction in the central nervous system. Horm Behav 63(2):322-330. https:// doi.org/10.1016/j.yhbeh.2012.02.020

325. Bortolato B, Miskowiak KW, Kohler CA, Maes M, Fernandes BS, Berk M, Carvalho AF (2016) Cognitive remission: a novel objective for the treatment of major depression? BMC Med 14:9. https://doi.org/10.1186/s12916-016-0560-3

326. De Crescenzo F, Lennox A, Gibson JC, Cordey JH, Stockton S, Cowen PJ, Quested DJ (2017) Melatonin as a treatment for mood disorders: a systematic review. Acta Psychiatr Scand 136(6):549558. https://doi.org/10.1111/acps.12755

327. Yubero-Serrano EM, Gonzalez-Guardia L, Rangel-Zuniga O, Delgado-Lista J, Gutierrez-Mariscal FM, Perez-Martinez P, Delgado-Casado N, Cruz-Teno C et al (2011) Mediterranean diet supplemented with coenzyme Q10 modifies the expression of proinflammatory and endoplasmic reticulum stress-related genes in elderly men and women. J Gerontol Ser A Biol Med Sci 67A(1):3-10. https://doi.org/10.1093/gerona/glr167

328. Mourier A, Motori E, Brandt T, Lagouge M, Atanassov I, Galinier A, Rappl G, Brodesser S et al (2015) Mitofusin 2 is required to maintain mitochondrial coenzyme Q levels. J Cell Biol 208(4): 429-442. https://doi.org/10.1083/jcb.201411100

329. Noh YH, Kim KY, Shim MS, Choi SH, Choi S, Ellisman MH, Weinreb RN, Perkins GA et al (2013) Inhibition of oxidative stress by coenzyme Q10 increases mitochondrial mass and improves bioenergetic function in optic nerve head astrocytes. Cell Death and Disease 4(10):e820. https://doi.org/10.1038/cddis.2013.341 
330. Genova ML, Lenaz G (2011) New developments on the functions of coenzyme Q in mitochondria. Biofactors 37(5):330-354. https://doi.org/10.1002/biof.168

331. Cotan D, Cordero MD, Garrido-Maraver J, Oropesa-Avila M, Rodriguez-Hernandez A, Gomez Izquierdo L, De la Mata M, De Miguel M et al (2011) Secondary coenzyme Q10 deficiency triggers mitochondria degradation by mitophagy in MELAS fibroblasts. FASEB J 25(8):2669-2687. https://doi.org/10.1096/fj.10165340

332. Morris G, Anderson G, Berk M, Maes M (2013) Coenzyme Q10 depletion in medical and neuropsychiatric disorders: potential repercussions and therapeutic implications. Mol Neurobiol 48(3): 883-903. https://doi.org/10.1007/s12035-013-8477-8

333. Sanoobar M, Eghtesadi S, Azimi A, Khalili M, Khodadadi B, Jazayeri S, Gohari MR, Aryaeian N (2015) Coenzyme Q10 supplementation ameliorates inflammatory markers in patients with multiple sclerosis: a double blind, placebo, controlled randomized clinical trial. Nutr Neurosci 18(4):169-176. https://doi.org/10. 1179/1476830513y.0000000106

334. Sanoobar M, Eghtesadi S, Azimi A, Khalili M, Jazayeri S, Reza Gohari M (2013) Coenzyme Q10 supplementation reduces oxidative stress and increases antioxidant enzyme activity in patients with relapsing-remitting multiple sclerosis. Int J Neurosci 123(11):776-782. https://doi.org/10.3109/00207454.2013. 801844

335. Lee BJ, Huang YC, Chen SJ, Lin PT (2012) Coenzyme Q10 supplementation reduces oxidative stress and increases antioxidant enzyme activity in patients with coronary artery disease. Nutrition 28(3):250-255. https://doi.org/10.1016/j.nut.2011.06. 004

336. Alehagen U, Aaseth J, Johansson P (2015) Reduced cardiovascular mortality 10 years after supplementation with selenium and coenzyme Q10 for four years: follow-up results of a prospective randomized double-blind placebo-controlled trial in elderly citizens. PLoS One 10(12):e0141641. https://doi.org/10.1371/ journal.pone. 0141641

337. Mortensen SA, Rosenfeldt F, Kumar A, Dolliner P, Filipiak KJ, Pella D, Alehagen U, Steurer G et al (2014) The effect of coenzyme Q10 on morbidity and mortality in chronic heart failure: results from Q-SYMBIO: a randomized double-blind trial. JACC: Heart Failure 2(6):641-649. https://doi.org/10.1016/j. jchf.2014.06.008

338. Smith RAJ, Murphy MP (2010) Animal and human studies with the mitochondria-targeted antioxidant MitoQ. Ann N Y Acad Sci 1201(1):96-103. https://doi.org/10.1111/j.1749-6632.2010. 05627.x

339. Kelso GF, Porteous CM, Coulter CV, Hughes G, Porteous WK, Ledgerwood EC, Smith RAJ, Murphy MP (2000) Selective targeting of a redox-active ubiquinone to mitochondria within cells: antioxidant and antiapoptotic properties. J Biol Chem 276(7):4588-4596. https://doi.org/10.1074/jbc.m009093200

340. Lukashev AN, Skulachev MV, Ostapenko V, Savchenko AY, Pavshintsev VV, Skulachev VP (2014) Advances in development of rechargeable mitochondrial antioxidants. Progress Mol Biol Transl Sci Elsevier BV. https://doi.org/10.1016/b978-0-12394625-6.00010-6

341. Jin H, Kanthasamy A, Ghosh A, Anantharam V, Kalyanaraman B, Kanthasamy AG (2014) Mitochondria-targeted antioxidants for treatment of Parkinson's disease: preclinical and clinical outcomes. Biochim Biophys Acta (BBA) - Mol Basis Dis 1842(8): 1282-1294. https://doi.org/10.1016/j.bbadis.2013.09.007

342. Carvalho AF, Miskowiak KK, Hyphantis TN, Kohler CA, Alves GS, Bortolato B, GS PM, Machado-Vieira R et al (2014) Cognitive dysfunction in depression - pathophysiology and novel targets. CNS Neurol Disord Drug Targets 13(10):1819-1835

343. Forester BP, Harper DG, Georgakas J, Ravichandran C, Madurai N, Cohen BM (2015) Antidepressant effects of open label treatment with coenzyme Q10 in geriatric bipolar depression. J Clin Psychopharmacol 35(3):338-340. https://doi.org/10.1097/jcp. 0000000000000326

344. Lin H, Liu XB, Yu JJ, Hua F, Hu ZW (2013) Antioxidant Nacetylcysteine attenuates hepatocarcinogenesis by inhibiting ROS/ER stress in TLR2 deficient mouse. PLoS One 8(10): e74130. https://doi.org/10.1371/journal.pone.0074130

345. Machado JT, Iborra RT, Fusco FB, Castilho G, Pinto RS, Machado-Lima A, Nakandakare ER, Seguro AC et al (2014) NAcetylcysteine prevents endoplasmic reticulum stress elicited in macrophages by serum albumin drawn from chronic kidney disease rats and selectively affects lipid transporters, ABCA-1 and ABCG-1. Atherosclerosis 237(1):343-352. https://doi.org/10. 1016/j.atherosclerosis.2014.09.020

346. Sun Y, Pu L-Y, Lu L, Wang X-H, Zhang F, Rao J-H (2014) Nacetylcysteine attenuates reactive-oxygen-species-mediated endoplasmic reticulum stress during liver ischemia-reperfusion injury. World J Gastroenterol 20(41):15289-15298. https://doi.org/10. 3748/wjg.v20.i41.15289

347. Lee ES, Kim HM, Kang JS, Lee EY, Yadav D, Kwon MH, Kim YM, Kim HS et al (2016) Oleanolic acid and N-acetylcysteine ameliorate diabetic nephropathy through reduction of oxidative stress and endoplasmic reticulum stress in a type 2 diabetic rat model. Nephrol Dial Transplant 31(3):391-400. https://doi.org/ 10.1093/ndt/gfv377

348. Liu YY, Xie Q, Wang H, Lin LY, Jiang S, Zhou XQ, Yu H, Guo Q (2008) The effect of N-acetyl-L-cysteine on endoplasmic reticulum stress mediated apoptosis of HepG2 cells. Zhonghua gan zang bing za zhi $=$ Zhonghua ganzangbing zazhi 16(7):524-527

349. Berk M, Malhi GS, Gray LJ, Dean OM (2013) The promise of Nacetylcysteine in neuropsychiatry. Trends Pharmacol Sci 34(3): 167-177. https://doi.org/10.1016/j.tips.2013.01.001

350. Deepmala SJ, Kumar N, Delhey L, Berk M, Dean O, Spielholz C, Frye R (2015) Clinical trials of N-acetylcysteine in psychiatry and neurology: a systematic review. Neurosci Biobehav Rev 55:294 321. https://doi.org/10.1016/j.neubiorev.2015.04.015

351. Skvarc DR, Dean OM, Byrne LK, Gray L, Lane S, Lewis M, Fernandes BS, Berk M et al (2017) The effect of Nacetylcysteine (NAC) on human cognition - a systematic review. Neurosci Biobehav Rev 78:44-56. https://doi.org/10.1016/j. neubiorev.2017.04.013

352. Morris G, Walker AJ, Berk M, Maes M, Puri BK (2017) Cell death pathways: a novel therapeutic approach for neuroscientists. Mol Neurobiol. https://doi.org/10.1007/s12035-017-0793-y

353. Fernandes BS, Williams LM, Steiner J, Leboyer M, Carvalho AF, Berk M (2017) The new field of 'precision psychiatry'. BMC Med 15(1):80. https://doi.org/10.1186/s12916-017-0849-x 